Marc Felfe*

\title{
Marcello lächelt sein Mastroianni-Lächeln Marcello lächelt sein Mastroianni-Lächeln
}

\section{Kognate Objekte konstruktionsgrammatisch analysiert Cognate Objects analyzed Construction Grammatically}

https://doi.org/10.1515/zgl-2018-0023

\begin{abstract}
Sentences with a cognate object typically consist of an intransitive activity verb, its subject NP and a second NP in the accusative. Its nominal core is typically derived as nomen actionis and/or nomen acti from the verb.

Essential questions are: How are cognate objects licensed? What role do they play in verbal activity? Which nouns and which verbs come into question? Can the reading of cognitive objects be predicted as an event or object?

In this paper I will propose a constructional grammatical analysis. Different readings of the cognate object as well as the temporal constitution as a telic or atelic situation are explained within the construction by compositional processes. These are essentially analyzed as a transfer of the nominal reference mode to the entire VP. The nominal reference method also results from compositional processes within the NP. An important focus of the analysis is on overrides and adjustments (coercion) in case of semantic conflicts.
\end{abstract}

\footnotetext{
$1 \quad$ Einleitung

2 Ein- und Abgrenzung des Phänomens

2.1 Verben mit kognatem Objekt

2.2 Nominale Kerne kognater Objekte

2.3 Modifikation und Determination kognater Objekte

3 Analysen

3.1 Kognate Objekte: Argument oder Adjunkt?

3.2 Kognate Objekte als Telisierer?

3.3 Konstruktionsgrammatische Analysen

3.4 Ereignissemantische Analyse im HPSG-Format

$4 \quad$ Konstruktion und Komposition

4.1 Konstruktion als Lizenzierung kognater Objekte

4.2 Komposition und coercion

$5 \quad$ Fazit

Literatur
}

*Kontaktperson: Dr. Marc Felfe: Institut für deutsche Sprache und Linguistik, Humboldt-Universität zu Berlin, Unter den Linden 6, D-10099 Berlin, E-Mail: marc.felfe@german.hu-berlin.de 


\section{Einleitung}

Was soll man lächeln außer einem Lächeln? Und wie sollte man lächeln, ohne dass ein Lächeln entsteht? In diesem Sinne sollte an einer Äußerung wie Marcello lächelt sein Mastroianni-Lächeln ${ }^{1}$ nichts Auffälliges sein. Oder aber: Gerade durch jenen, auf den ersten Blick, tautologischen Ausdruck und die Tatsache, dass lächeln eigentlich intransitiv ist, wird sie auffällig. ${ }^{2}$ Auf der anderen Seite handelt es sich bei den Argumenten und der durch sie mit dem Verb ausgedrückten Handlung des Hervorbringens um ein im Deutschen etabliertes formal-semantisches Muster.

In dem vorliegenden Artikel geht es um die sogenannten kognaten Objekte. $^{3}$ An Publikationen dazu mangelt es nicht. Interessanterweise variiert jedoch die Bestimmung des Phänomens selbst je nach Autor. Folglich muss vor theoriegebundenen Analysen eine Bestimmung des Begriffs geleistet und diskutiert werden.

Daher geht es im ersten Abschnitt um die Ein- und Abgrenzung von Äußerungen mit kognatem Objekt. Die Darstellung gründet auf der Fachliteratur und qualitativ ausgewerteten Daten aus DeReKo, ${ }^{4}$ dem DWDS-Korpus ${ }^{5}$ sowie aus dem Internet. Die aus DeReKo erhobenen Belege von lächeln mit kognatem Objekt werden auch quantitativ betrachtet. Auf dieser Grundlage werden Antworten auf die folgenden strittigen Fragen vorgeschlagen: Welche Verben kommen in Frage? Werden nur intransitive Verben wie lächeln als Instanzen der KO-Konstruktion gewertet oder auch transitive Verben wie bauen oder fischen, wenn das Objekt morphologisch mit dem Verb verwandt ist wie in einen modernen Bau bauen oder Fische fischen? Wie lässt sich der Unterschied zwischen den Hass hassen und einen tiefen Hass hassen erklären? Interessanterweise werden in kaum einer Publikation die nominalen Kerne kognater Objekte genauer betrachtet. Daher werden sowohl Form und Referenzweise als auch mögliche Variationen untersucht. Bezüglich der eingangs angesprochenen Tautologie stellt sich die Frage nach dem grundlegenden semantischen Unterschied zwischen dem Verb lächeln und der Infinitivkonversion (das) Lächeln. Bezüglich der Variation ist nach dem Unterschied zwischen ein tiefes Seufzen seufzen und einen tiefen Seufzer seufzen

1 Süddeutsche Zeitung, 27.11.2001, S. V2/10.

2 Daher spricht Paul (1881/2007: 336, S§ 59) in seiner Mittelhochdeutschen Grammatik vom „tautologischen Akkusativ“.

3 Kognate Objeke werden alternativ u. a. von Paul (1919: 226) als innere Objekte oder von Helbig (1973: 169) als Akkusativ des Inhalts bezeichnet.

4 https://cosmas2.ids-mannheim.de/cosmas2-web/

5 https://www.dwds.de 
zu fragen. Warum sind Ausdrücke wie ??ein weites Werfen werfen im Gegensatz $\mathrm{zu}$ einen weiten Wurf werfen nicht belegt? Man kann ein freundliches Lächeln lächeln - aber kann man es auch schmunzeln und umgekehrt ein kleines Schmunzeln lächeln? Welche Rolle spielen die Modifikatoren und Determinatoren kognater Objekte? Die Semantik der Nomen und Nominalphrasen wurde bisher kaum beachtet. Ihre Analyse bildet den Hintergrund, vor dem besondere Eigenschaften von Äußerungen mit kognatem Objekt erklärt werden können.

Im zweiten Abschnitt werden verschiedene Analysen vorgestellt und diskutiert. Die Besonderheit, dass die kognaten Objekte nicht vom entsprechenden Verb lizenziert sein müssen (oder ist lächeln doch transitiv?), führt zu der Frage nach ihrem Status. Handelt es sich um Argumente oder Adjunkte? Wie kann der Unterschied zwischen appositiven NP wie in sie kämpften, ein harter Kampf und kognaten Objekten sie kämpften einen harten Kampf adäquat erfasst werden? In diesem Beitrag werden kognate Objekte als syntaktische und semantische Argumente analysiert. Im Anschluss werden Vorschläge im Rahmen der Konstruktionsgrammatik und der HPSG diskutiert. Es wird gezeigt, dass die vorgeschlagenen Konstruktionen und Regeln in Bezug auf die im ersten Abschnitt diskutierten Daten zu spezifisch sind.

Daher wird im dritten Abschnitt eine unterspezifizierte konstruktionsgrammatische Analyse vorgeschlagen. Die verschiedenen Lesarten und Eigenschaften von Äußerungen mit kognaten Objekten lassen sich konstruktionsintern kompositionell herleiten. Hierin liegt die Besonderheit dieser Analyse. Weder die Semantik der Nomen (nomen actionis/acti) noch die Zeitkonstitution von Äußerungen mit kognatem Objekt als telische oder atelische Situationsbeschreibungen sind auf Grund der Tatsache, dass es sich um kognate Objekte handelt, vorhersagbar. Diese Eigenschaften ergeben sich aus den Komponenten der Konstruktion und ihrem Zusammenspiel. Daher sollten sie nicht, wie bisher, an die Lizenzierung kognater Objekte selbst gebunden werden.

\section{Ein- und Abgrenzung des Phänomens}

Beginnen wir unsere Betrachtung nicht auf der Wort-, sondern Satzebene. Der holistische Blick auf die Argumentstruktur erlaubt es erst einmal, wesentliche formale und semantische Gemeinsamkeiten von Sätzen mit kognatem Objekt (in Folge KO) zu erfassen. Sie bestehen aus einer NP im Nominativ, einem Verb oder Verbalkomplex und einer NP im Akkusativ. Deren nominaler Kern ist in der Regel morphologisch mit dem Verb verwandt. Hierauf zielt die Bezeichnung ,kognat (blutsverwandt) ab. Typischerweise wird der nominale Kern des KO modifiziert, 
wodurch die entsprechende NP komplex ist. Äußerungen mit KO drücken aus, dass ein Agens durch die vom Verb bezeichnete Tätigkeit das KO hervorbringt. Daher wird es in Arbeiten zum Englischen und Deutschen häufig als effiziertes Objekt bezeichnet. ${ }^{6}$ In diesem Sinne kann der folgende Beleg als typischer Vertreter von Sätzen mit KO gesehen werden (1).

(1) Lieselotte Feuerschütte lächelt ein verzaubertes Lächeln [... $]^{7}$

Während der holistische Blick vorerst ein recht homogenes Bild ergibt, führt die Betrachtung der internen Teile zu Fragen der Ein- und Abgrenzung von Konstruktionen mit KO. Diese Fragen werden im Folgenden gestellt, wenn unter 2.1 die Verben, unter 2.2 die nominalen Kerne und unter 2.3 die Modifikations- und Determinationsmuster von KO besprochen werden.

\subsection{Verben mit kognatem Objekt}

Formal fallen besonders Verben auf, die wie lächeln als intransitiv gelten, aber zusammen mit einem KO gebraucht werden. Hierbei handelt es sich mehrheitlich um Verben, die nach Vendler (1957) der Gruppe der activity-Verben zuzuordnen sind. ${ }^{8}$ Typische Vertreter sind einen harten Kampf kämpfen oder eben das bereits erwähnte ein verzaubertes Lächeln lächeln. Neben den klassischen activity-Verben kommen auch zahlreiche Verben in KO-Konstruktionen vor, die körperliche Prozesse denotieren, welche mehr oder weniger willentlich gesteuert werden. Ein typischer Vertreter dieser Gruppe ist das Verb schlafen in (2).

(2) Der Dichter schläft einen befreienden Schlaf $[. . .]^{9}$

Intransitive, atelische Verben wie kämpfen und schlafen können insofern zum Kernbereich der Verben mit KO gezählt werden, als dass sie unstrittig in allen Publikationen zu den KO besprochen, teilweise sogar als Definitionsgrund-

6 Cf. Brugmann (1903: 441f, § 561.2b), Helbig (1973: 61), Bausewein (1990: 74), Macfarland (1995), Mittwoch (1998), Kuno \& Takami (2004). - ,Effizierte Objekte‘ stehen somit im Gegensatz $\mathrm{zu}$,affizierten Objekten', deren Denotate unabhängig von der Verbalhandlung existieren und von dieser betroffen sind.

7 Braunschweiger Zeitung, 17.04.2007.

8 Hierunter versteht Vendler (1957: 146) dynamische Prozesse, deren zeitlicher Verlauf homogen ist, d.h. „,any part of the process is of the same nature as the whole“.

9 Nürnberger Nachrichten, 29.02.2008, S. 2. 
lage gewertet werden. So bestimmt de Swart (2007: 35, 39) Intransitivität und Zugehörigkeit zur Klasse der activity-Verben als Zugangsvoraussetzung zu KOKonstruktionen. Punktuelle telische Verben (3a) sind von der KO-Konstruktion ausgeschlossen, was insbesondere Partikel- und Präfixverben betrifft. Punktuelle (also schwach durative) atelische Verben können mit KO gebraucht werden. Dies mag daran liegen, dass viele punktuelle Verben wie niesen, treten oder husten auch iterativ verstanden und gebraucht werden können. Durch den Gebrauch mit einem KO wie in (3b) wird eine mögliche Iterativität zu Gunsten eines punktuellen Verständnisses blockiert. Umgekehrt kann der Gebrauch mit einem KO auch die punktuelle Lesart zu Gunsten einer iterativen blockieren (3c). Dies wird in 2.2 bei der semantischen Analyse der nominalen Kerne der KO erklärt. Im Gegensatz zu den activity-Verben können Zustandsverben wie glänzen, stinken anstelle eines KO mit einem kognaten Subjekt (3d) gebraucht werden. Allerdings sind analogische Ausdehnungen vom Prototyp der activity-Verben mit KO möglich (3e,f), insbesondere dann, wenn entsprechende Verben analog $\mathrm{zu}$ den activity-Verben über eine Output-Komponente verfügen.

(3) a. *Er wacht ein schnelles Aufwachen auf.

b. Das wird nun auch einem gemütlichem Büffel wie Bodhi zu viel und er niest einen ohrenbetäubend lauten Büffelnieser. ${ }^{10}$

c. Und mein Vater schielt aus dem Fenster, schüttelt den Kopf, hustet seinen trockenen Husten [...] $]^{11}$

d. Der alte Glanz glänzt matter inzwischen [... $]^{12}$

e. Sie schien von der Masse fast zerquetscht zu werden, strahlte aber wieder dieses maskenhafte Strahlen $[. . .]^{13}$

f. Das Tüpfelchen auf dem i: Seife stinkt diesen hässlichen Pseudomoschus-gestank. ${ }^{14}$

Bei einer feinkörnigeren Betrachtung der Verben, welche mit KO belegt sind, lassen sich diese verschiedenen semantischen Gruppen zuordnen. So schreiben auch Höche (2009: 274) und Handwerker (2010: 20), dass primär Verben auffallen, deren gemeinsames Merkmal eine Art von Emission oder Output ist. Hierzu gehören einen lauten Pfiff pfeifen, ein schallendes Lachen lachen, einen tiefen

10 http://www.simonefaltermaier.me/uploads/3/4/9/3/34937651/bodhi_buch_final_klein-1.pdf

11 Braunschweiger Zeitung, 06.11.2010.

12 Süddeutsche Zeitung, 11.10.2012, S. 41.

13 Der Spiegel, 29.05.2000, S. 192.

14 https://www.vielfliegertreff.de/airports-lounges/190-duschen-lounges-gute-undschlechte-3.html 
Seufzer seufzen und davon abgeleitet auch Kommunikationsverben wie ein leises Flüstern flüstern oder den Schrei der Sieger schreien. Dies ist nicht verwunderlich, da doch die Gesamtausdrücke, wie eingangs beschrieben, das Hervorbringen einer Entität denotieren. Eine weitere semantische Untergruppe stellen (Fort-) Bewegungsverben dar, welche wie in (4) gebraucht werden.

(4) a. Hier fliegt Led Zeppelin seinen weichen, schweren Flug. ${ }^{15}$

b. Der erste Flug nach Tokio wurde über Sibirien geflogen. ${ }^{16}$

c. [...] wird/werden die Berechtigung/die Berechtigungen [...] - auf der Rückseite der Lizenz durch den Fluglehrer verlängert, der den Schulungsflug mit Ihnen geflogen hat. ${ }^{17}$

Hermann Paul (1919: 218f.) bespricht solche Fälle als freieren (ursprünglichen) Gebrauch des Akkusativs zum Ausdruck der Raumerstreckung. Dies entspricht dem heute gängigen Konzept vom adverbialen Akkusativ des Raumes. ${ }^{18}$ Nun macht aber Paul (ebd.: 219) gerade darauf aufmerksam, dass jene Wegerstreckung auch als inneres (kognates) Objekt verstanden werden kann. Analog zu typischen effizierten Objekten lassen sich Wege und Strecken als eine Entität verstehen, welche vom Verb hervorgebracht werden. Die Passivierung in (4b) sowie die Wahl des Perfektauxiliars haben (statt sein) in (4c) werte ich als wichtiges Indiz für eine Bestimmung als kognates Objekt. ${ }^{19}$

Im Folgenden wird der Frage nachgegangen, welche intransitiven Verben nicht mit KO vorkommen. Winkler (2009: 128) macht darauf aufmerksam, dass die Zugehörigkeit zu semantischen Gruppen oder aber die Ähnlichkeit zu einem konkreten Verb kaum Vorhersagen darüber zulassen, ob ein konkretes Verb mit KO gebraucht wird oder nicht. Neben dem frequenten KO-Gebrauch von lächeln finden sich nach Winkler (ebd.) keine Belege für grienen und gackern und nur einer für kichern. Engelberg (2000: 125) bezweifelt Bildungen wie „??eine schwere Blutung bluten, ??einen lauten Rülpser rülpsen“. Für die von Engelberg als fraglich gekennzeichneten Bildungen (5a,b) und die von Winkler nicht belegte Verwendung von grienen und gackern mit $\mathrm{KO}(5 \mathrm{c}, \mathrm{d})$ finden sich jedoch seltene Belege. ${ }^{20}$

15 Die Zeit, 31.03.1995, Nr. 14.

16 Kleine Zeitung, 26.04.2000.

17 Regierungspräsidium Darmstadt: Informationen zur Privatpilotenlizenz PPL(A) nach VO (EU) 1178/2011, S. 2.

18 U. a. in der Dudengrammatik (2016: 816, § 1246).

19 Cf. ebenso Bausewein (1990: 59).

20 Ähnliches fällt auf, wenn bei Mittwoch (1998: 313) She slept a long sleep mit einem Fragezeichen versehen ist. Höche (2009: 125) weist korpuslinguistisch nach, dass das Verb to 
(5) a. Fürs Vaterland, zu bluten des Herzens Blut ${ }^{21}$

b. Er rülpst einen langen, lauten, stinkenden Rülpser. ${ }^{22}$

c. [...] und grient sein breitestes Grienen, ungelogen von einem Ohr zum andern. $^{23}$

d. Beverly zischte ihr Echsenzischen, Patrick kreischte sein Affenkreischen und Dennis der Hahn gackerte sein Hahnengackern. ${ }^{24}$

Offensichtlich sollte die Analyse des Phänomens nicht zu restriktiv sein. Viele seltene Belege und Einmalbelege (Hapax Legomena) sprechen für ein gewisses Produktivitätspotential bei intransitiven activity-Verben. Es sind dann eher Fragen des Stils und Geschmacks, welche die potentiell möglichen Bildungen hemmen oder fördern. ${ }^{25}$ Die Rolle des Stils und epochenabhängigen Geschmacks wird deutlich, wenn Reiner (1986: 21) schreibt, dass das Ausschöpfen des systematisch Möglichen auch zu Bildungen führe, welche gerade nicht im Sinne einer rhetorischen Figur stilistisch elegant seien. Die Grammatik sollte sie aber zulassen. Ruge (2015: 443) verweist auf Schriften aus dem 15. Jahrhundert, in welchen vor dem exzessiven Gebrauch von KO gewarnt wird. $\mathrm{Zu}$ diesem kam es, so Ruge (ebd.: 431), in Texten des sogenannten ,geblümten Stils‘ im 13. und 14. Jahrhundert. ${ }^{26}$

Betrachten wir nun zwei Sonderfälle intransitiver Verben, nämlich Dativverben und die sogenannten unakkusativischen Verben. Nach Handwerker (2010: 21) verweigern Dativverben eine Valenzerweiterung durch ein KO. Als unmögliches Beispiel führt sie , ${ }^{\star}$ Er huldigte dem König eine Huld“ auf. Es ist jedoch nicht klar, warum ein solcher Gebrauch ausgeschlossen sein sollte. Das ursprüngliche Dativargument und das KO im Akkusativ geraten weder in einen semantischen noch in einen formalen Konflikt. Das Gesamtmuster wäre zudem

sleep zusammen mit dem Nomen sleep als KO unter den 25 häufigsten von 3139 Verben mit KO ist. Offensichtlich ist die Angst vor Übergeneralisierungen viel größer als die sprachliche Realität.

21 Friedrich Hölderlin: Der Tod fürs Vaterland. In: Sämtliche Werke. Frankfurter Ausgabe. Herausgegeben von D. E. Sattler. Band 2. Frankfurt am Main: Roter Stern, S. 410.

22 https://www.fanfiktion.de/s/449311f90000302c06d00bbe/4/The-Day-After-Tomorrow

23 Heinz Strunk: Der goldene Handschuh. Rowohlt Verlag, 2016.

24 Alexander London: Wir retten die Welt. Arena Verlag, 2015.

25 So zeigt Ruge (2015: 422, 424), dass der KO-Gebrauch vom Mittelhochdeutschen zum Neuhochdeutschen abgenommen hat, aber auch innerhalb des Mittelhochdeutschen stark nach Autor, Übersetzungsvorlage und Zeitschnitt variiert.

26 Auch später findet sich entsprechende Kritik. Adelung (1782: 822) schreibt, dass der im Verb enthaltene Begriff nicht als Objekt wiederholt werden dürfe und lehnt „einen Kampf kämpfen, einen Streit streiten“ ab. Allerdings bemerkt er, dass „ein elendes Leben“ anstelle des korrekten „elend leben“ gängig sei. 
durch die etablierte ditransitive Argumentstruktur gedeckt, falls das verbale Dativargument neben dem KO ausgedrückt wird. ${ }^{27}$ So verwundert es nicht, dass sich tatsächlich Belege finden lassen (6).

(6) a. man sollte auch die benutzung der autobahnen unter strafe stellen, schließlich wird da nachträglich dem führer die huldigung gehuldigt. ${ }^{28}$

b. Als der Mensch aber, der er ist, als der homo humanus, der er ist, hat er den gleichen Dienst gedient, indem er stets, wo es galt, für die Ganzheit und Einigkeit des Menschenwesens eintrat. ${ }^{29}$

c. Du bist mein Engel ohne Flügel $\bullet$ ich danke dir für all die Hilfe die du mir geholfen hast! ${ }^{30}$

d. Sportstadtrat Günther Stürz dankte allen Mitarbeitern Dank für die Umsetzung des Projekts. ${ }^{31}$

Äußerungen wie in (6) sind selten. Aber auszuschließen sind sie nicht, so lange es sich um activity-Verben handelt. Anzumerken ist, dass es sich bei Dank danken (6d) eher um eine Pseudo-Inkorporation als um ein echtes KO handelt. Hierauf wird unter 2.2 noch einmal eingegangen.

Unakkusativische Verben gelten mit Ausnahme von einen grausamen Tod sterben u. a. nach Macfarland (1995: 198) und Mittwoch (1998: 313) als unzulässig für KO. ${ }^{32}$ Tatsächlich sollten jene Verben aus zwei Gründen mit KO inkompatibel sein: das Subjekt ist kein Agens, sondern unterliegt dem vom Verb ausgedrückten Prozess, ist also eine Art Prozessträger. Und dieser Prozess ist telisch, d. $h$. das Subjekt unterliegt einer Zustandsveränderung. ${ }^{33}$ Bausewein (1990: 32) merkt jedoch bereits an, dass eine Bildung wie einen tiefen Fall fallen eventuell möglich wäre und sieht keine so absolute Trennlinie zwischen intransitiven activity- und

27 Das im Mittelhochdeutschen hochfrequente „slâc slan“ (cf. Ruge 2015: 423) wird häufig mit Dativ verwendet so wie in dem folgenden Beleg aus Hartmanns Iwein: „sluoc im der rise einen slag“. Referenzkorpus Mittelhochdeutsch unter https://www.linguistics.rub.de/rem/. Beleg unter: https://www.linguistics.rub.de/annis/annis3/?id=8f86da4b-6f96-4c4a-8a7b-d6b4e9d6e $8 \mathrm{cb}$.

28 https://hessenhenker.wordpress.com/2013/10/09/strafanzeige-ans-finanzministeriumwegen-hitlergrus/

29 Martin Buber: Festrede zu Hesses 80. Geburtstag. Neue deutsche Hefte. August 1957. Stuttgart.

30 http://www.thepicta.com/user/_pati33dl_/2018092464

31 Tiroler Tageszeitung, 11.04.2000.

32 Macfarland (1995: 197) macht kurzerhand aus to die ein unergatives Verb.

33 Da der Begriff ,unakkusativisch` üblich geworden ist, übernehme ich ihn. Passender wäre es, wie Kaufmann (1995: 163f.) vorschlägt, von „Thema-Verben“ zu sprechen. 
unakkusativischen Verben in Bezug auf KO. Für das Englische führen Kuno \& Takami (2004: 116) Belege mit unakkusativischen Verben auf. Für das Deutsche habe ich einen Beleg mit wachsen und verschiedene mit fallen und stürzen.

(7) a. Dank dir, Jungfrau, schöne Jungfrau,/Daß du deine Treu bewahret,/Daß du deinen Wuchs gewachsen. ${ }^{34}$

b. Alles wurde dunkel und er fiel einen tiefen Fall ins Nichts, das ihn umfasste. ${ }^{35}$

c. Er stürzte, stürzte den Sturz der Verdammten, endlos, unter ihm war nur Abgrund. ${ }^{36}$

Wie lässt sich der Gebrauch der Verben in (7) erklären? Das Verb wachsen impliziert eine gewisse Zeitspanne, anders als das ebenfalls unakkusativische ankommen. Es ist nun gut möglich, dass jene Durativität den Gebrauch mit einem KO begünstigt. Durativität als Zugang zu den KO vermutet auch Handwerker (2010: 22) bei sterben in einen qualvollen Tod sterben. Der Eintrag $\mathrm{zu}$ „sterben“ im Deutschen Wörterbuch der Gebrüder Grimm bestätigt das: Neben der punktuellen telischen Lesart (achievement) hat sterben auch eine durative Lesart. Diese Lesart begründe ungewöhnliche Perfekt-Belege mit dem Hilfsverb haben wie „länger denn ein ganzes Jahr hat er immer gestorben“37 sowie die Kombination mit durativen Adverbialen wie „nicht diese stunde nur, sie starb viel lange tage“ (Klopstock). ${ }^{38}$ Der Gebrauch mit KO kann nun, je nach Modifikation von Tod als Ausdruck jener latent angelegten Durativität verstanden werden. Bei fallen und stürzen ist durch die jeweilige ,Fallhöhe“ ebenfalls eine begrenzt durative Lesart möglich. Ebenso sollte ihr Gebrauch mit KO in Analogie zu den besprochenen Verben der Fortbewegung betrachtet werden. Der wesentliche Unterschied zu den übrigen Verben mit KO ist, dass die sogenannten unakkusativischen Verben mit KO im Perfekt ausschließlich mit dem Auxiliar sein gebraucht werden. Der Grund hierfür dürfte die mangelnde Transitivität sein, an der sich auch durch den Gebrauch mit einem KO nichts ändert. Bildlich gesprochen, setzt sich die Selektion der Verben gegenüber der KO-Konstruktion durch.

34 Joh. Gottfried Herder: Sämtliche Werke, 4. Esthnische Hochzeitslieder, S. 104.

35 https://alainfux.wordpress.com/2016/11/12/268-als-iwo-wieder-sein-bewusstsein-erlangtestand-er-auf-einer-rampe-aus-rohem-beton/

36 Otto Gmelin: Das Angesicht des Kaisers. Jena: E. Dietrichs, 1927, S. 267.

37 Paul Majunke (1891): Luthers Lebensende. Eine historische Untersuchung. 5. Auflage. Mainz: Kupferberg, S. 80.

38 Deutsches Wörterbuch von Jacob und Wilhelm Grimm. 16 Bde. in 32 Teilbänden. Leipzig 1854-1961. Ich beziehe mich auf die online-Version: http://woerterbuchnetz.de/cgi-bin/WBNetz/ wbgui_py?sigle=DWB. 
Wie sieht es nun mit transitiven Verben in Bezug auf KO aus? De Swart (2007: 42) schließt für das Englische transitive Verben, deren Objekt nicht durch die Verbhandlung hervorgebracht wird, von KO-Konstruktionen aus. Ein verbal angelegtes affiziertes Patiens-Argument blockiere den Gebrauch mit einem KO. Massam (1990: 166) hat hingegen gezeigt, dass der Gebrauch mit einem KO möglich ist und dann das verbale Argument blockiert. Dies ist im Deutschen auch der Fall und wird u.a. von Bausewein (1990: 75f.) gezeigt. Durch das KO verändert sich die Lesart insofern, als dass die eigentlich affizierenden Verben nun effizierend verstanden werden. Betrachten wir hierzu die folgenden Belege.

(8) a. [...] denn die Italiener seien in ihrer Mentalität den Wienern ähnlich und liebten die Liebe, gutes Essen und Musik [... $]^{39}$

b. Der Trierer Bischof Stephan Ackermann untermauerte in seiner Predigt [...], wie die katholische Kirche „menschenwürdiges Leben und Sterben“ sieht: „Sein ganzes Leben leben, seine ganze Liebe lieben, seinen ganzen Tod sterben. “40

c. [...] als dass ich das Gefühl gehabt hätte, ich hätte einen Schlag geschlagen, den ich zuvor noch nie geschlagen habe. ${ }^{41}$

d. Bitte kein Selbstversuch! Lassen Sie den Schnitt durch den Profi schneiden. ${ }^{42}$

In (8a) wird im Sinne des Defaultgebrauchs von lieben die Liebe geliebt. Das Verbalgeschehen richtet sich auf das Objekt, affiziert es. In (8b) hingegen wird eine Liebe hervorgebracht. In (8c) wird niemand geschlagen, sondern ein Schlag erzeugt. Genauso in (8d), wo nichts schneidend geteilt, sondern ein Schnitt erzeugt wird.

Die Besonderheit und die Gemeinsamkeit der intransitiven sowie dieser transitiven Verben besteht in Folgendem: sie drücken durch den Gebrauch mit einem KO ein Hervorbringen-Ereignis aus, welches nicht mit ihnen - wenigstens nicht primär oder nicht mehr ${ }^{43}$ - assoziiert wird.

39 Nürnberger Nachrichten, 11.11.2014, S. 2.

40 Die Zeit, 31.03.1995.

41 NZZ am Sonntag, 20.01.2013, S. 49.

42 Braunschweiger Zeitung, 26.09.2009.

43 Bei Paul (1919: 241) und Behaghel (1923: 688) wird eine ganze Gruppe von Verben besprochen, die sowohl eine affizierende als auch eine effizierende Lesart haben oder hatten. So z. B. jdn. schlagen vs. Wunden schlagen oder den Acker pflügen vs. eine Furche pflügen. Jene Varianz beruht grundlegend auf Implikaturen über metonymischen und Ursache-Folge-Beziehungen. 
Ganz im Gegensatz dazu finden sich Ausdrücke mit KO, in denen transitive Verben die mit ihnen assoziierten Ereignisse ausdrücken. In den folgenden Belegen werden bauen, schreiben und weben ohne grammatische oder semantische Auffälligkeiten gebraucht. Die jeweils hervorgebrachten Objekte sind morphologisch mit dem Verb verwandt und wesentlicher Bestandteil der Verbbedeutung.

(9) a. 1984 hatten Vereinsmitglieder den schmucken Bau in Eigenleistung gebaut. ${ }^{44}$

b. Der TÜV hat nämlich sehr komische Schreiben geschrieben. ${ }^{45}$

c. Drehbuch und Regie weben dabei feinsinnig ein durchaus sentimentales Gewebe. ${ }^{46}$

Dass Konstruktionen dieser Art von Sailer (2010: 192), Mittwoch (1998: 313) und Ágel (2017: 646) nicht zu den KO gezählt werden, ist nachvollziehbar. Ihnen zufolge handelt es sich um ein rein stilistisches Phänomen. Das im Verb angelegte zweite Argument wird durch einen Ausdruck realisiert, welcher nicht nur morphologisch vom Verb abgeleitet ist, sondern gleichfalls eine determinierende Bedeutungskomponente des Verbs ist. Entsprechende Verbindungen von Wörtern gleichen Stammes werden seit dem 19. Jahrhundert figura etymologica genannt. ${ }^{47}$ In diesem Sinne handelt es sich bei einen Bau bauen genauso wie bei ein Reiter reitet um stilistische, nicht aber um grammatische Besonderheiten. Durch die lexikalische Lizenzierung des zweiten Arguments handelt es sich bei einen Bau bauen oder ein Schreiben schreiben zwar nicht um Instanzen der KO-Konstruktion. ${ }^{48}$ Aber sie müssen in der Analyse berücksichtigt werden. Denn gerade von jenen lexikalisch lizenzierten, aber stilistisch auffälligen Verwendungen lässt sich eine (mindestens) synchrone Brücke $\mathrm{zu}$ KO-Verwendungen mit intransitiven oder transitiven affizierenden Verben schlagen. Somit kann der Gebrauch intransitiver activity-Verben mit KO strukturell als eine Ausdehnung vom Prototyp transitiver effizierender Verben gesehen werden. Dieser Bezug tritt dann deutlich zu Tage, wenn die verba efficiendi mit einem morphologisch verwandten Objekt gebraucht werden. Das kann stilistisch auf etablierten intransitiven Verben beruhen, welche

44 Braunschweiger Zeitung, 04.02.2012.

45 Protokoll der Sitzung des Parlaments Landtag Niedersachsen am 01.07.1998. 7. Sitzung der 14. Wahlperiode 1998-2003. Plenarprotokoll, Hannover, 1998.

46 St. Galler Tagblatt, 01.03.2012, S. 12.

47 Cf. Mayer (1996: Spalten 279-282) In: Historisches Wörterbuch der Rhetorik. Band 3. Herausgegeben von Gert Ueding. Tübingen: Niemeyer, 1996.

48 Im Englischen zählt Höche (2009: 40) to build a building zu den KO. Im Deutschen geht Winkler (2009: 126) ebenso vor. Begründet wird es jedoch von beiden Autorinnen nicht. 
häufig mit einem KO gebraucht werden. Das Muster der Argumentstruktur für KO beruht aber auf den verba efficiendi. Anders wäre kaum zu erklären, warum die grammatisch und/oder semantisch auffälligen KO-Typen ein formal-semantisch etabliertes und heute im Sinne von verbalen Argumentstrukturen gefestigtes Form-Funktionsmuster nutzen. ${ }^{49}$

Zählen wir einen Bau bauen zum Prototyp, dessen analogische Ausdehnung KO sind, dann stellt sich mit Ágel (2017: 645) zu Recht die Frage nach den Grenzen der KO. Diese Frage stellt sich umso mehr, da zum Beispiel Höche (2009: 89) auch to feet some food (,Futter (ver-)füttern') und to fish some fish (,Fische fischen') zu den KO zählt. Winkler (2009: 137) bestimmt auch eine instrumentale PP mit stammverwandten Lexemen wie mit der Kettensäge sägen als KO. Wenn, so wie eingangs, holistisch von Form-Funktions-Zusammenhängen ausgegangen wird, so zählen nur transitive Muster zu den KO, die ausdrücken, dass das KO durch das verbale Tun hervorgebracht wird. Daher handelt es sich weder bei affizierten Objekten (Fische fischen) noch bei klassischen Angaben (mit der Kettensäge sägen) um KO-Konstruktionen. Hier wird die figura etymologica ausgeschöpft, aber nicht das formal-semantische Muster zum Ausdruck des Hervorbringens einer Entität.

Bevor es im Folgenden um die nominalen Kerne der KO geht, sei an dieser Stelle die große Varianz der möglichen Verben und Verbtypen hervorgehoben. Den Kernbereich stellen intransitive activity-Verben dar. Das formale Muster von KO-Konstruktionen wurde auf effizierende Verben bezogen, wenn diese mit einem stammverwandten Objekt gebraucht werden. Alle gleichförmigen Ausdrücke, in denen nicht das Hervorbringen einer Entität ausgedrückt wird, wie Fische fischen, zählen nicht dazu. Ursprünglich transitive affizierende Verben verändern bei Gebrauch mit einem KO ihre Lesart und drücken wie einen tiefen Hass hassen oder einen modischen Schnitt schneiden das Hervorbringen des KO aus. Aus denotativer Perspektive lässt sich fragen, ob Experiencer-Verben wie hassen und lieben beim Gebrauch mit einem KO tatsächlich das Hervorbringen von Hass und Liebe bedeuten. Dies mag angesichts des Gefühlslebens mechanistisch erscheinen. Ebenso mag bei träumen eingewandt werden, dass ein bestimmter Traum der Inhalt und nicht das effizierte Patiens des Träumens ist. Aus signifikativer Perspektive handelt es sich jedoch darum, dass das Konzept des Hervorbringens analogisch ausgedehnt wird, und zwar auf Grundlage des bestehenden Ausdrucksmodells.

49 So, aber kommentarlos, geht Brugmann (1903: 441, § 561) vor. Er bespricht zuerst die klassischen verba efficiendi (ein Haus erbauen) und im Anschluss die intransitiven Verben, die wie verba efficiendi gebraucht werden (einen tiefen Schlaf schlafen). In beiden Fällen handele es sich um den „Akkusativ des inneren Objektes“. 


\subsection{Nominale Kerne kognater Objekte}

Als unumstritten gelten KO, deren nominaler Kern mit dem Verb morphologisch verwandt ist. In aller Regel handelt es sich dabei um Nominalisierungen des Verbs. Somit stellen die Nomen Kampf in einen harten Kampf kämpfen und Lächeln in ein freundliches Lächeln lächeln typische Vertreter der nominalen Kerne von KO dar. In diesem Abschnitt geht es um folgende Fragen: Lassen sich Nominalisierungsmuster ausmachen, die typisch für KO sind? Wie lässt sich deren Semantik mit Bezug auf die verbale Basis beschreiben? Das Hauptaugenmerk liegt auf der Referenzweise der Nominalphrasen. Referieren sie wie NPs mit Individualnomen oder wie NPs mit Massennomen. Denn das wird eine zentrale Rolle bei der Analyse der Zeitkonstitution von Äußerungen mit KO spielen. Des Weiteren geht es um die Frage der Variation: Wird ein Verb mit verschiedenen von ihm abgeleiteten Nomen als KO gebraucht? Wie werden Nomen analysiert, die nur semantisch mit dem Verb verwandt sind wie einen schweren Tod sterben?

Betrachten wir zunächst die verschiedenen Nominalisierungsmuster, auf welchen KO beruhen. Wenn sich Konversionen des Verbstamms im Sprachgebrauch etabliert haben, so werden diese typischerweise als KO genutzt (10a). Dies gilt auch für die sogenannten impliziten Derivationen mit Wechsel des Stammvokals (10b) und die ebenfalls heute nicht mehr produktiven Stammderivata z. B. mit -e (eine große Liebe lieben) und - $t$ (eine Höllenfahrt fahren), welche jedoch viel seltener sind.

(10) a. Der Kuckuck rief seinen Ruf nur zur Hälfte [... $]^{50}$

b. Gewinner ist, wer am Ende des Monats den höchsten Wurf geworfen hat. $^{51}$

Gibt es entsprechende Formen nicht, so werden Infinitivkonversionen genutzt bzw. gebildet (10c). Mitunter finden sich parallel zu etablierten Bildungen oder aber zu Infinitivkonversionen auch Derivata mit dem Suffix -er (10d) und selten Ableitungen mit dem Affix Ge-(-e) (10e). Bildungen mit -ung (10f) werden offensichtlich nur dann gebraucht, wenn sie im Sprachgebrauch fest etabliert und ohne Konkurrenz durch Stammkonversionen und implizite Derivata sind.

50 Die Zeit, 03.07.1959, S. 9.

$51 \mathrm{http}: / /$ www.gasthaus-feyen.de/?page=53\&type=news 
(10) c. Sie lacht ein rauchiges Lachen. ${ }^{2}$

d. Diesen Seufzer, den schon Roland Barthes seufzte, könnte man ausstoßen, wenn man die Augen-Blicke auf den Fotos von Stefan Süess betrachtet. ${ }^{53}$

e. Zwischen Tram und Auto und Hochbahn/Wird das alte Geschrei geschrien. ${ }^{54}$

f. Hoffe die Hoffnung! $!^{55}$

Auch hier zeigt sich ähnlich wie bei den Verben eine recht große Varianz um einen formalen (Konversion) und um einen semantischen Kernbereich, um den es nun geht.

Viele verschiedene Formen der deverbalen Nominalisierung weisen eine Gemeinsamkeit auf. Mehrheitlich dienen bzw. dienten sie der Bildung von nomina actionis. Hierunter werden Substantive verstanden, welche ein Geschehen, einen Prozess oder eine Handlung - im Gegensatz zu einem Resultatsobjekt - bezeichnen. Paul (1919: 226) und Behaghel (1923: 715) erwähnen nur jene Verbalabstrakta im Zusammenhang mit kognaten Objekten. Entsprechende Sicht findet sich in der englischsprachigen Literatur u.a. bei Massam (1988) und Moltmann (1989), die KO als „eventive objects“ beschreiben. Brugmann (1903: 441, § 561.2b) geht differenzierter vor. Er bezeichnet die klassischen effizierten Objekte als Resultatsobjekte, welche die Handlung überdauern (danach da sind). Das Denotat der KO sei hingegen nur während der Verbaltätigkeit da und ende mit dieser. Daher schreibt er von Erscheinungen und Vorgängen. Dies scheint erst einmal plausibel, wenn wir einen Bau bauen oder ein Schreiben schreiben mit ein ein Seufzen seufzen vergleichen. Unter 2.1 wurden jedoch auch affizierende transitive Verben betrachtet, die mit einem KO effizierend verstanden werden. Bei einen Schnitt schneiden sind beide Lesarten möglich, die als nomen acti (einen modischen Schnitt schneiden) und die als nomen actionis (einen sicheren Schnitt schneiden). Aber selbst bei Infinitivkonversionen kann neben einer primären eventiven Lesart (Vorgang, Handlung) eine Objektslesart möglich sein. Diese wird zum Beispiel durch modifizierende Adjektive ausgelöst. So verstehen wir das Lächeln in (11a) eher als nomen acti, in (11b) hingegen eher als nomen actionis.

52 Die Zeit, 03.05.2010, Nr. 18.

53 Süddeutsche Zeitung, 27.06.2002, S. 18.

54 B. Brecht: Die Medea von Lodz. In: Gesammelte Werke in 8 Bänden. 4. Band. Frankfurt am Main, 1967, S. 518.

55 taz, 25.05.2013. 
(11) a. Am Ende darf sie sogar ein halbes Lächeln lächeln, direkt in die Kamera. ${ }^{56}$

b. Er lächelte ein schnelles Lächeln und nahm seinen erregten Monolog sofort wieder auf. ${ }^{57}$

In der Literatur testet meinem Wissen nach nur Sailer (2010: 196) die verschiedenen Lesarten. ${ }^{58}$ Dies tut er jedoch außerhalb der KO-Konstruktionen und bestimmt die Lesart von the smile in (12a) als nomen actionis und in (12b) als nomen acti.

(12) a. But the smile lasted less than a heartbeat. ${ }^{59}$

d. A smile appeared on his face.

Dies zeigt erst einmal nur, dass das Nomen smile zwei Lesarten haben kann. Grimshaw (1990: 48) schreibt diesbezüglich, dass selbst innerhalb der Klasse der nomina actionis eine „fundamental ambiguity“ zwischen nominaler Resultats- und verbal-aspektualer Prozess-Lesart bestehe. ${ }^{60}$ In Bezug auf die KO gehen auch Höche (2009), Winkler (2015) und Sailer (2010) von beiden Lesarten aus. ${ }^{61}$ Wesentlich ist nun aber, die möglichen Lesarten innerhalb der jeweiligen KOKonstruktion zu testen und nicht außerhalb. Solche Tests für die Lesart als nomen actionis sind u. a. die Kombination mit Prädikaten, welche Ereignisse selegieren und bestimmte Zeitabschnitte ausdrücken (13a). Ebenso kann getestet werden, ob die Nomen mit Adjektiven bzw. Modifikatoren gebraucht werden, welche den Verlauf modifizieren (13b) oder Iterativität ausdrücken (13c). ${ }^{62}$

56 Süddeutsche Zeitung, 12.04.2000, S. 17.

57 Die Zeit, 15.04.1960, S. 9.

58 Horrocks \& Stavrou (2010: 296) erwähnen die beiden möglichen Lesarten und halten die Ereignislesart für die typische bei KO. Innerhalb von Äußerungen mit KO werden die Lesarten nicht geprüft.

59 Die Beispiele sind Sailer (2010: 197) entnommen.

60 Nur bei Ereignislesart mit vom Verb geerbten Argumenten spricht Grimshaw (1990: 48) von aspektueller Lesart. Somit analysiert sie „John's examination was long“ als nicht aspektuelle NP, da John Modifikator „possessor, author, or taker of the exam“ sein kann. Hingegen habe das deverbale Nomen in ,John's examination of the patiens took a long time.“ die Argumentstruktur des Verbs mit John als Agens und dem Patienten als Patiens geerbt und somit aspektuelle Lesart. 61 Mittwoch (1988: 312) und Macfarland (1995: 61) erkennen ein gewisses Changieren zwischen den Lesarten an.

62 Cf. Ehrich \& Rapp (2000: 252-254) und Grimshaw (2011: 1293, 1300). 
(13) a. Sie lächelte ein Lächeln, das nie wieder aufhören sollte. ${ }^{63}$

b. Er sagte es ihr, endlich lächelte sie ihr vorsichtiges Lächeln [... ${ }^{64}$

c. Als „sehr konzentriert und sehr akribisch“, hat Babbel das belanglose Tun beschrieben - und dabei sein übliches Lächeln gelächelt, das immer dann die Antworten des ehemaligen Weltklassespielers begleitet, wenn ihm eine Fragestellung nicht so ganz kompetent erscheint. ${ }^{65}$

Die Belege in (13) sprechen dafür, das Substantiv Lächeln innerhalb der KO-Konstruktion als Ereignis-Nomen zu bestimmen. Erstaunlich ist, dass sich ebenfalls Belege finden, welche für eine Objektlesart sprechen. In (14a) wird Lächeln mit einem Prädikat physischer Veränderung und in (14b) mit einem Prädikat der Verortung gebraucht. In (14c) ist Lächeln durch ein Adjektiv modifiziert, das eine physische Eigenschaft (Form, Gestalt, Größe) beschreibt.

(14) a. „Ich wirke hart?“, fragt Marga Prohens im Interview und lächelt wieder ihr weiches, nettes Lächeln, das sie scheinbar auf dem Weg ins Parlamentsgebäude stets abzulegen pflegt, wenn sie sich in die Vollblutpolitikerin verwandelt. ${ }^{66}$

b. Er steht auf, geht auf Erika Meier zu und lächelt ein Lächeln, das aus tiefstem Herzen kommt. ${ }^{67}$

c. Da lächelt Ecevit ein großes, breites Lächeln. ${ }^{68}$

Die Belege in (14) sprechen eher für eine Objektlesart. Das ist wesentlich. Denn es zeigt, dass die KO-Konstruktion selbst mögliche Ambiguitäten nicht auflöst. Dies ist eher eine Frage der Modifikation, um die es im nächsten Abschnitt geht. Bei einer Lesart als nomen actionis stellt sich jedoch die Frage, worin dann der Unterschied zwischen Verb und Nomen bzw. nominalisiertem Verb liegt. Dies wird im Folgenden in Anlehnung an Langackers (1987, 1991) Cognitive Grammar ${ }^{69}$ und Krifkas (1989) Untersuchung der Nominalreferenz thematisiert.

Langacker (1991: 13) geht zur grundlegenden konzeptuellen Unterscheidung von Verb und Nomen vom Billardmodell als kognitivem Grundmuster aus. Diesem folgend lässt sich die Welt aus physisch diskreten Entitäten und ener-

\footnotetext{
$63 \mathrm{http} / / /$ www.kaithomasgeiger.de/71/pasta-baby

64 Rhein-Zeitung, 19.08.2008.

65 Die Welt, 14.12.2011.

66 Mallorca Zeitung, 01.07.2017.

67 https://www.ovb-online.de/politik/die-krise-schweisst-zusammen-5538868.amp.html

68 taz, 03.08.2002, S. 28.

69 Diesen Ansatz verfolgen auch Iwasaki (2007) und Höche (2009).
} 
getischen Interaktionen zwischen diesen konzeptualisieren. ,Entität ' steht abstrakt für Objekte, Beziehungen, Orte, Empfindungen, Punkte auf Skalen und Entfernungen. Nach Langacker (1991: 13f.) bilden räumlich ausgedehnte Entitäten den Prototyp des Nominalkonzepts. Die zeitlich ausgedehnten Interaktionen und Prozesse bilden den Prototyp des Verbalkonzeptes. Hieraus folgt, dass Nomen typischerweise einen räumlich abgrenzbaren Bereich von miteinander verbundenen Entitäten evozieren. Langacker (ebd.: $15 \mathrm{f}$.) führt als Beispiel Nomen wie Stern und Wagen (für das Sternbild) auf. Er (1991: 18f.) charakterisiert jene Nomen als „bounded“. ${ }^{70}$ Es handelt sich um das klassische Konzept der Zählbarkeit. ${ }^{71}$ Krifka (1989: 39) führt in Anlehnung an Quine (1960) den Begriff der Quantelung ein und begründet die Zählbarkeit mereologisch. Verfügt ein Nomen über gequantelte Referenz, so fällt ein Teil seines Denotats nicht unter das gleiche Nomen. Gibt es zwei Denotate, die jeweils unter ein Nomen fallen, so fällt ihre Summe nicht unter das gleiche Nomen. Dies kann anhand des Nomens Bau in Der Fuchs baut seinen Bau wie folgt dargestellt werden. Ein Teil des Denotats von Bau ist selbst kein Bau. Zwei Denotate, die jeweils unter Bau fallen, fallen zusammen nicht unter das gleiche Prädikat, sondern unter $z w e i$ Baue.

Im Gegensatz zu den gequantelten Individualnomen gibt es auch die sogenannten Massennomen. Deren Referenzweise ist nach Quine (1960: 91) kumulativ. Dies kann am Beispiel von Schlaf aus einen tiefen Schlaf schlafen deutlich gemacht werden. Ein Teil des Denotats von Schlaf fällt auch wieder unter das Prädikat Schlaf. Zwei Entitäten, die jeweils unter das Prädikat Schlaf fallen, fallen zusammen unter das gleiche Prädikat. Das zentrale Merkmal jener Abstrakta ist interne Homogenität bei fehlender $\mathrm{Ab}$ - und Eingrenzung. ${ }^{72}$ Deverbale Nomen

70 Langacker (1991: 19) beschreibt jene „Eingrenzung“ der Individualnomen im Gegensatz zu den Massennomen mittels der Merkmale „homogeneity, contractibility, replicability“. Ein Individualnomen kann, aber muss nicht intern homogen sein. Es muss sich vor einem (konzeptuellen) Hintergrund klar abgrenzen. Ein Teil der Instanz eines Massennomens ist auch wieder Instanz des gleichen Nomens, was bei Individualnomen nicht der Fall ist. Wenn zur Instanz eines Individualnomens eine zweite Instanz des gleichen Nomens hinzugefügt wird, dann handelt es sich um zwei separate Instanzen. Im Gegensatz dazu fallen zwei Instanzen eines Massennomen wieder unter das gleiche nominale Prädikat.

71 Jespersen (1924: 198): „While countables are ,quantified“ by means of such words as one, two, many, few, mass-words are quantified by means of such word as much, little, less.“

72 Davon abzugrenzen sind atomare, d. h. nicht homogene Kollektivbezeichnungen wie Möbel, die ebenfalls kumulativ referieren. Krifka (1989: 40) thematisiert „das Problem der kleinsten Teile“. Für die Semantik natürlicher Sprachen lässt er die Frage der Atomarität offen und plädiert für das Kriterium der kumulativen Referenz. 
können wie Bau (in seiner Lesart als nomen acti) gequantelt und wie Schlaf kumulativ sein. Dies wird bei den klassischen Tests ${ }^{73}$ deutlich (15).

(15) a. ein Bau, zwei Baue - vs. Schlaf

b. eine Stunde Schlaf - vs. ? Bau

c. viel/etwas/mehr/lauter/aller Schlaf - vs. *viel/etwas/mehr/lauter/aller Bau

d. Er braucht Schlaf. - vs. ${ }^{\star}$ Er braucht Bau.

Im Gegensatz dazu bezeichnen Verben Relationen zwischen Entitäten (typischerweise Partizipanten). Jene Verbindungen werden als zeitlich aufeinander folgende Sequenzen von Zuständen konzeptualisiert. Langacker (1987: 145, 248) schreibt im Gegensatz zu einem konzeptuellen „summary scanning“ bei Nomen von einem „sequential scanning“ bei Verben. Dem Nominalkonzept liegt eine Gestalt zugrunde, welche im Falle der Prozesslesart aus simultanen und additiv verbundenen Zuständen besteht. Hierin besteht auch bei nomina actionis die Verdinglichung (Hypostasierung). Welke (2016: 72f) schreibt diesbezüglich: „Substantivkonstruktionen mit deverbalem Kopf, und zwar einschließlich nomina actionis, werden zunächst (d.h. prototypisch) gemäß dem Bilateralitätsprinzip auch semantisch als Substantivkonstruktionen, d.h. als Dingbeschreibungen (oder weniger provokant, weil die protypische Verschiebung andeutend: Gegenstandsbeschreibungen) und nicht als Situationsbeschreibungen, interpretiert.“ (Hervorhebung im Original).

Das Verbalkonzept basiert hingegen auf der sukzessiven Abfolge von Zuständen, von denen ein jeder relational ist. Bildlich gesprochen lasse sich die nominale Konzeptualisierung mit der Betrachtung eines Fotos und die verbale mit dem Sehen eines Filmes vergleichen. Bei imperfektiven (atelischen) Prozessen sind jene Zustandssequenzen identisch (homogen konstruiert), so dass ein Teil des Prozesses unter das gleiche Prädikat fällt. Bei perfektiven (telischen) Prozessen unterscheiden sich die Zustandssequenzen voneinander, so dass ein Teil des Prozesses nicht unter das gleiche Prädikat fällt. Somit können das Verbalkonzept und die nominale Referenzweise aufeinander bezogen werden. Imperfektive (atelische) Prozesse ähneln der Referenz von NPs mit Massennomina, perfektive Prozesse den NPs mit Individualnomen. ${ }^{74}$

73 Cf. Krifka (1989: 4).

74 Der Vergleich nominaler Referenzweise mit verbalen Konzepten entspricht der ereignissemantischen Perspektive. Dieser zufolge referieren Verben auf Ereignisse, deren Argumente stark in der Verbbedeutung angelegte Merkmale determinieren. Das gegenläufige Prinzip der Prädika- 
Für unsere Zwecke sind nun die für KO relevanten Modelle der deverbalen Nominalisierung wesentlich. Grundlegend lassen sich verschiedene vom Verb evozierte Bedeutungskomponenten durch Nominalisierung profilieren. Von zweiwertigen effizierenden Verben wie etwas bauen lassen sich grundsätzlich das erste verbale Argument als nomen agentis (der Erbauer) sowie das Produkt (der Bau) profilieren. Die wie KO gebrauchten Nomen (einen Bau bauen) weisen Objekt- (der Bau steht dort) und Ereignislesart auf (der Bau dauerte zwei Jahre). Die mit ihnen gebildeten NPs referieren wie NPs mit Individualnomen, d. h. gequantelt.

Wie ist es aber, wenn das Verb nur einwertig ist und gar nicht über ein effiziertes Argument verfügt? Es sei kurz daran erinnert, dass intransitive activityVerben den verbalen Kernbereich der KO-Konstruktion darstellen. In diesem Fall sind für die KO-Bildung vier konzeptuelle Muster von Bedeutung. Trotz Intransitivität wird der Output oder der Inhalt des Verbalgeschehens als Objekt profiliert. Dies ist bei dem ,dinglich verortbaren' Lächeln in (14) der Fall und kann auf eine ganze Gruppe von deverbalen Nomen zutreffen: schneiden - der Schnitt, träumen - der Traum, schreien - der Schrei.

Hier handelt es sich hauptsächlich um Stammkonversionen und implizite Derivationen. Entsprechende Nomen sind typischerweise gequantelt und referieren daher wie Individualnomen. Diese Konzeptualisierung zeigt sich untypischerweise auch bei Lächeln (16), welches ja nicht zum formalen Muster der Stammkonversion oder impliziten Derivation gehört.

(16) [...] in beiden Mundwinkeln spielte beständig ein Lächeln, man hätte fast sagen können zwei Lächeln [.....$^{75}$

Eingedenk der thematisierten Ambiguität können jene Nomen auch episodisch, d. h. als nomina actionis verstanden werden. Langacker (1991: 24) schreibt von einer „single episode“ des vom Verb ausgedrückten Geschehens. Das deverbale Nomen extrahiere aus der vom Verb ausgedrückten Folge identischer Zustandssequenzen einen Teil (eine Episode). Diese Episode bezeichnet Brinton (1995: 35) als „some arbitrarily bounded stretch“ des Verbalgeschehens. Jene Arbitrarität ergibt sich daraus, dass die Sequenzen bei atelischen Verben identisch sind. Die Verdinglichung besteht nun darin, dass jene Auszüge des Verbalgeschehens nicht als zeitliche Abfolge, sondern simultan, d.h. holistisch konzeptualisiert werden (summary scanning). Dies ist z. B. bei der Ereignislesart von Lächeln, Schrei,

tion als Merkmalszuweisung vom Verb (Prädikat) an die Denotate der Argumente wird nicht verneint, spielt in dieser Betrachtung jedoch keine Rolle.

75 Leo Tolstoi: Krieg und Frieden. Null Papier Verlag, 2012, S. 69. 
Schnitt der Fall. Langacker (1987: 247) schreibt, dass hierbei die Nominalisierung die Komponenten des entsprechenden Prozesses als ein Set miteinander verbundener Entitäten profiliere und darüber das kollektive Profil einer Entität lege. Typischerweise (nicht so bei Schlaf) sind NPs mit diesen Nomen als Kern gequantelt. Hierin unterscheidet sich die gequantelte Nominalreferenz von dem ungequantelten (imperfektiven) Verbalkonzept. Allerdings führt die Ereignislesart zu schwächerer Quantelung. So kann zwar der Plural von Kampf gebildet werden, das heißt zwei Denotate, die jeweils unter Kampf fallen, fallen zusammen nicht unter Kampf, sondern unter zwei Kämpfe. Allerdings ist unklar, ab wann ein Teil des Denotats nicht mehr unter das gleiche Prädikat fällt. Ab wann ist der Teil eines Kampfereignisses kein Kampf mehr? Dies zeigt sich auch darin, dass Kampf als Abstraktum wie ein Massennomen gebraucht werden kann (17).

(17) a. Am Ende war aller Kampf vergeblich. ${ }^{76}$

b. Aber wir dürfen vor lauter Kampf nicht vergessen, dass unsere Stärke im Spielerischen liegt. ${ }^{77}$

c. Ballack fordert mehr Kampf. ${ }^{78}$

d. Das war Kampf! ${ }^{79}$

Eine ganz spezielle Art der verbalen Sequenzextraktion stellen die Derivata mit -er wie in einen tiefen Seufzer seufzen dar. Durch -er wird exakt eine der verbalen Sequenzen extrahiert. In Bezug auf KO geht es um Verben der Lautäußerung (seufzen - Seufzer) und der Bewegung (hopsen - Hopser). Profiliert wird also ein Moment aus dem Verbalverlauf mit der Bedeutung Einzelheit (Quantelung) in Prozess- und Objektlesart. ${ }^{80}$ Allerdings ist diese Bildung stark durch die Konkurrenz zur gleichförmigen Bildung der nomina agentis restringiert.

Im Gegensatz zu den typischerweise gequantelten Stammkonversionen und Derivata mit Ereignis- und Objektlesart sind Infinitivkonversionen ungequantelt. Mit ihnen gebildete NPs referieren daher wie NPs mit Massennomen. Von Lexikalisierungen wie das Schreiben und mehr oder weniger etablierten Objektlesarten wie das Lächeln abgesehen, handelt es sich um nomina actionis. Bierwisch

76 Rhein-Zeitung, 15.04.1996.

77 Rhein-Zeitung, 17.03.2007.

78 Hamburger Morgenpost, 06.02.2008.

79 MK Kreiszeitung 06.05.13.

80 Draeger (1996: 64f.) bezeichnet Dinglichkeit (statt Prozesshaftigkeit) als ein wesentliches Merkmal dieses Typs. M. E. kann jener Vorgangsmoment immer auch prozessual verstanden werden. Hierfür sprechen Äußerungen wie: „Der Ungedulds-Seufzer beginnt mit einem feuchten Schnalzen am Gaumen [...].“ John le Carré: Der wachsame Träumer. Berlin: Ullstein, 2006. 
(1989: 34) bezeichnet Infinitivkonversionen als „the most regular and systematic event noun in German“. Bei Infinitivkonversionen handelt es sich im Gegensatz zu den Derivata gerade nicht um die Extraktion einer Episode des Verbalgeschehens. Nach Langacker (1991: 26) wird das verbale „sequential scanning“ auch zu Gunsten einer holistischen Konzeptualisierung des Ereignisses aufgelöst. Jedoch werden die inneren Komponenten komplett homogen als Abstraktum konstruiert. Dies lässt sich anhand der Infinitivkonversion telischer Ausdrücke zeigen. Während etwas zerstören und das abgeleitete Resultats- oder Ereignisnomen die Zerstörung gequantelt sind, ist dies bei das Zerstören nicht mehr der Fall. Der Teil einer Zerstörung ist keine Zerstörung. Hingegen fällt ein Teil des Denotats von Zerstören auch wieder unter Zerstören. Jene interne Homogenität führt dazu, dass die Grenzen des Nominalkonzepts beliebig eingrenzbar und erweiterbar sind, wodurch sich Infinitivkonversionen wie Massennomina verhalten. Ganz ähnlich sind die Derivata mit Ge-(-e). Abgesehen von lexikalisierten Objektbezeichnungen wie in ein Gebäck backen referieren sie kumulativ auf eine unbegrenzte Vielheit von homogenen Verbalsequenzen wie das eingangs aufgeführte ein lautes Geschrei schreien. Hinzu kommt eine negative Konnotation, welche Olsen (1991: 352) auf „das Iterativmoment der Grundbedeutung“ zurückführt.

Bevor ein Blick auf die Variation zwischen Verb und KO geworfen wird, seien die wesentlichen formal-semantischen Eigenschaften der nominalen Kerne von KO zusammengefasst. NPs mit Stammkonversionen und Derivata können sowohl auf Ereignisse als auch auf Objekte referieren. Die KO-Konstruktion selbst löst entsprechende Ambiguität nicht auf. Sowohl Objekte als auch Ereignisse haben wir als Entität bezeichnet. Für beide Lesarten gilt das grundlegende Nominalkonzept des „summary scanning“. Nominal ausgedrückte Prozesse und Vorgänge werden holistisch als simultan und additiv verbundene Zustände konzeptualisiert. Typischerweise sind Stammkonversionen und Derivata gequantelt und entsprechende NPs referieren daher wie NPs mit Individualnomen. Die gequantelte Referenzweise von NPs mit Individualnomen ähnelt perfektiven Situationsdarstellungen. Bei Ereignislesart handelt es sich um die Profilierung eines beliebigen Ausschnitts aus dem Verbalgeschehen. Daher referieren die NPs mit entsprechenden Nomen schwächer gequantelt als bei Objektslesart. NPs mit Ableitungen mit -er referieren auf genau eine Sequenz des Verbalgeschehens und sind somit gequantelt. Infinitivkonversionen profilieren das Verbalgeschehen ebenfalls holistisch auf dem konzeptuellen Muster des „summary scanning“. Allerdings wird das Geschehen vollkommen homogen profiliert, was die Kumulativität begründet. Daher referieren NPs mit Infinitivkonversionen wie NPs mit Massennomen und ähneln imperfektiven Situationsdarstellungen. Bei jenen Form-Funktions-Beziehungen handelt es sich um Tendenzen. Strikte Vorhersagen von der Form zur Bedeutung oder umgekehrt sind nicht möglich. Denn hier überschnei- 
den sich produktive Bildungen (das Seufzen, der Seufzer) mit lexikalisierten Formen produktiver Prozesse (das Schreiben in Objektlesart) und Nomen, deren Bildungsmuster nicht mehr produktiv sind (der Schlaf). Dennoch liegt der Vorteil dieser Analyse darin, von formalen Nominalisierungsmustern auszugehen und sie auf zwei verschiedene Referenzweisen, nämlich die gequantelte oder die kumulative zu beziehen. Es handelt sich um eine Präzisierung der rein extensionalen Sicht von Horrocks \& Stavrou (2010: 296), denen zufolge jedes Ereignis irgendwann beginnt und irgendwann endet. ${ }^{81}$

Im Folgenden wird die mögliche Variation der nominalen Kerne von $\mathrm{KO}$ als eine Quelle von Produktivität betrachtet. Typischerweise gilt die bereits beschriebene Präferenz: Stammkonversionen und Derivata scheinen den Gebrauch von Infinitivkonversionen zu blockieren. So finden sich keine Belege für \#ein schweres Kämpfen kämpfen oder \#ein tiefes Schlafen schlafen. Geringe Variation gibt es aber bei Verben der Lautäußerung zwischen Ereignis profilierenden Infinitivkonversionen (18a) und Derivata mit -er (18b), welche eine einzelne Sequenz des Geschehens verdinglicht profilieren. In der semantischen Differenz liegt die Motivation dieser Variation. In (18b) wird durch die Quantifikation des KO im Gegensatz zu (18a) Iterativität ausgedrückt.

(18) a. [...] zwei Tage später hieß es in der „FAZ“, Schröder solle bei einem Treffen mit Gewerkschaftern in Berlin „,sein Lachen gelacht haben, welches ehedem gerne als Wolfslachen beschrieben wurde“.${ }^{82}$

b. So lacht der Hauptmann einige seiner expressiven Lacher gleich in der ersten Szene asynchron an Celli und Bässen vorbei. ${ }^{83}$

Handelt es sich bei den Derivata auf -er um etablierte Bildungen wie bei Seufzer und Schluchzer im Gegensatz zu Nieser und Huster, so werden diese gegenüber den Infinitivkonversionen bevorzugt gebraucht.

Selten finden sich parallel auch KO-Varianten mit dem Affix $\mathrm{Ge}$-(e) (19). Hier liegt der semantische Mehrwert in der besprochenen Referenz auf eine Vielheit homogen konstruierter Verbalsequenzen sowie in der negativen Konnotation.

81 Cf. Krifka (1989: 237) zum Problem einer rein extensionalen Bestimmung der Begriffe, perfektiv/imperfektiv‘ und ,Zählbarkeit/Unzählbarkeit‘.

82 Der Tagesspiegel, 18.09.2005.

83 Mannheimer Morgen, 04.04.2005. 
(19) a. [...] und beide lachen das Gelächter der Ausbeutung. ${ }^{84}$

b. „Besser als nichts“, fauchte der große Warla, heulte sein heuligstes Geheul $[. . .]^{85}$

Wie sieht es nun mit Variation auf der Grundlage des gleichen Bildungstyps aus, wenn es sich um semantisch verwandte Verben als Ableitungsbasis handelt? Winkler (2009: 128) hält Kombinationen wie ein Grinsen lächeln oder ein Schmunzeln lächeln für unmöglich. Im Englischen scheiden nach Massam (1990: 165) entsprechende Kombinationen ebenfalls aus. Gegenbelege aus dem Englischen finden sich bei Kuno \& Takami (2004: 118-122), die von „[n]on-cognate ,cognate“ objects“ schreiben. Auch im Deutschen finden sich Belege, in denen das KO nicht von dem Verb der entsprechenden Konstruktion abgeleitet wurde, sondern von einem semantisch verwandten Verb (20). Mitunter ist die Variation zwischen Verb und KO beidseitig, was anhand von (20a,b) sowie (20e,f) veranschaulicht wird.

(20) a. Bisher schlummern die Biobauern den Schlaf der Gerechten. ${ }^{86}$

b. Haben die Übrigen die Nase voll von unserer Demokratie oder schlafen sie den süßen Schlummer unserer geliebten Konsumgesellschaft? ${ }^{87}$

c. Irgendwann zieht sich der Tiger brummend zurück und die derangierte Dompteuse grinst ihr breitestes Lächeln. ${ }^{88}$

d. Mit spitzen Zähnen grient er das Lächeln von J. R. Ewing [... $]^{89}$

e. Nadine Roll schmunzelt ihr bezauberndes Lächeln. ${ }^{90}$

f. Oft lächelt der ehemalige Chefkommentator des DDR-Fernsehens [...] sein legendäres süffisantes Schmunzeln. ${ }^{91}$

Ohne Frage sind bis auf einen qualvollen Tod sterben typische KO morphologisch von dem Verb abgeleitet, mit welchem sie gebraucht werden. Belege wie die in (20) sind zwar viel seltener als die typischen KO-Konstruktionen. So finden sich in DeReKo 505 Belege mit ein Lächeln lächeln, hingegen nur dreizehn für ein Lächeln grinsen, einer für ein Lächeln grienen, zwei für ein Lächeln schmunzeln und einer

84 die tageszeitung, 20.11.2002, S. 25.

85 Mannheimer Morgen, 06.10.2001.

86 die tageszeitung, 18.01.2007, S. 21.

87 Mannheimer Morgen, 23.11.1999.

88 Nürnberger Zeitung, 08.04.2005.

89 Süddeutsche Zeitung, 23.08.1993, S. 13.

90 Nordkurier, 11.09.2010.

91 Berliner Morgenpost, 17.12.1998, S. 6. 
für ein Schmunzeln lächeln. ${ }^{92}$ Aber die Vielfalt möglicher Variation ist erstaunlich und widerlegt entsprechende Einschränkungen aus der Fachliteratur. ${ }^{93}$ Ich gehe mit Kuno \& Takami (2004: 121) und de Swart (2007: 42) davon aus, dass KO als effizierte Objekte mit dem Verb kompatibel sein müssen. Dies bedeutet, das Nomen muss Ereignisse oder Objekte bezeichnen, welche als Resultat des vom Verb ausgedrückten Geschehens konzeptualisierbar sind. So ist erklärlich, dass ein Lachen als KO normalerweise nicht mit dem Verb lächeln kombiniert wird..$^{94}$ Denn lächeln bezeichnet eine stimmlose Geste, wohingegen Lachen zusätzlich etwas Hörbares ausdrückt. Darüber hinaus werden offensichtlich bestimmte Inkompabilitäten bewusst zum Ausdruck von Ironie genutzt. So bedeutet das Verb grinsen in (20c) ein spöttisch-böses oder dümmliches Lächeln, während Lächeln primär ein positiv konnotierter Ausdruck der Freude ist. Der Grad jener Variation liegt primär am Grad der lexikalischen Ausfächerung semantisch sehr ähnlicher Bereiche. Bei schmunzeln, grienen, lächeln, grinsen ist diese Ausfächerung relativ groß. Entscheidend ist, dass jene Variation nicht nur auf Hyponymie beruht, wie Sailer (2010: 210) vermutet. Schmunzeln und Grienen sind keine Hyponyme von Lächeln. Sie stehen eher als Ko-Hyponyme auf einer Stufe bezüglich einer abstrakten Geste, die sich durch nach oben gezogene Mundwinkel beschreiben ließe.

Die dargestellte mögliche Variation im Nominalbereich macht es nötig, dass Phänomen der KO ein- und abzugrenzen. Real-Puigdollers (2008: 158) plädiert im Englischen dafür, nur morphologisch vom Verb abgeleitete Nomen (mit Ereignislesart) als KO zu klassifizieren. Handelt es sich um semantisch verwandte Nomen, so schreibt sie von einer „Hyponymic Object Construction“. Sie illustriert das anhand von einen Tanz/einen Tango/einen Walzer... tanzen. Analog zur Behandlung der transitiven effizierenden Verben in 2.1 wird wie folgt vorgegangen. Als Muster für die KO-Bildung zählen bei transitiven effizierenden Verben nur diejenigen Nomen, welche vom Verb abgeleitet sind. Dazu gehören einen Tanz tanzen und einen Bau bauen, nicht aber einen Tango tanzen oder einen Wolkenkratzer bauen. Bei letzteren handelt es sich um gewöhnliche Objekte, nämlich um Ausbuchstabierungen dessen, was als zweites Argument vom Verb stark präsupponiert wird. Wie in 2.1 dargelegt, ist der Unterschied ein stilistischer und bildet im

92 Suchanfrage innerhalb des DeReKo im Korpus „W-öffentlich - alle öffentlichen Korpora des Archivs W (mit Neuakquisitionen)“ am 04. 11.17. Komposita wurden nicht berücksichtigt.

93 Cf. Sailer (2010: 204).

94 Ich habe einen Beleg dafür gefunden: „Dann lächelt er sein großes Zähnelachen in die Fotoapparate seines Volkes.“ (die tageszeitung, 10.01.2000, S. 11). Das Verb und der Kontext führen zu einem ,stimmlosen` Verständnis von ,Lachen` auf einem Foto. Übrig bleibt eine Geste des Lachens, welche sich durch einen weiter bzw. überhaupt geöffneten Mund von ,Lächeln` abhebt. 
Falle von einen Bau bauen eine Brücke zum verbbasierten formal-semantischen Muster des Effizierens.

Anders sieht es bei Verben wie lächeln aus, die eigentlich intransitiv sind, dennoch durch Gebrauchshäufigkeit mit einem KO assoziiert werden (ein Lächeln lächeln). Wenn ein anderes Nomen anstelle des lizenzierten KO steht, so zählt es unter dem Stichwort ,Varianz' mit zu den KO (ein Schmunzeln lächeln). Denn offensichtlich besetzt es die als KO angelegte Argumentstelle. Das Gleiche trifft $\mathrm{zu}$, wenn ausgehend vom häufigen Typ ein Lächeln lächeln die Verbstelle variant realisiert wird. Bei ein Lächeln schmunzeln ist das KO auch nicht mit dem Verb verwandt. Nur sollte das in DeReKo zweimal belegte ein Lächeln schmunzeln sicher nicht als Variation des ebenfalls zweimal belegten ein Schmunzeln schmunzeln behandelt werden, sondern umgekehrt als Variante des frequenten ein Lächeln lächeln. Grundsätzlich vermute ich nach Analyse der Korpusbelege, dass häufige Variation im KO-Bereich neben der lexikalischen Ausfächerung auf häufig gebrauchten Mustern basiert. Das stünde im Einklang mit der Erkenntnis, dass prototypische Extensionen von häufigen Vertretern einer Kategorie ausgehen, müsste aber bezüglich der KO statistisch geprüft werden.

Zum Schluss sei noch auf einen Konstruktionstyp wie in (21) hingewiesen, welcher heute etwas archaisch anmutet und im 18. Jahrhundert besonders viel genutzt wurde. ${ }^{95}$

(21) a. Eine der weißen Vestageweihten/lächelte Gnade dem Todbereiten. ${ }^{96}$

b. [...] aber mein Auge funkelt Rache, mein Mund schnaubt Wuth [...]. ${ }^{97}$

Für Hermann Paul (1919: 230 f.) sind solche Konstruktionen mit den kognaten Objekten verwandt, da etwas in der Verbbedeutung Enthaltenes oder damit Verbundenes ausgedrückt wird. Auch für Behaghel (1923: 718) besteht eine gewisse Ähnlichkeit. Jedoch lässt er es offen, ob hier eine Ableitung aus dem KO-Typ vorliegt. Besonders ist, dass die Nomen in (21) so wie die heute gängigen Ausdrücke Bruderschaft trinken oder Angst und Wasser schwitzen typischerweise artikellos und ohne Modifikatoren verwendet werden. Daher handelt es sich um pseudoinkorporierte Prädikatsteile und nicht um KO. Semantisch ist dieses Muster auch nicht auf das Hervorbringen von etwas festgelegt. Genauso kann wie in Krieg blasen oder in Sturm laufen (Sturm in der ursprünglichen Verwendung von Kampf,

95 Cf. Dal (2014: 12).

96 Rainer Maria Rilke: Eine der weißen Vestageweihten. In: Rainer Maria Rilke. Die Gedichte. Herausgegeben von Ernst Zinn. 13. Auflage. Insel, 2002, S. 106.

97 Johann Benjamin Erhard: Denkwürdigkeiten des Philosophen und Arztes J. B. E. Cotta, 1820, S. 92. 
Krieg) der Zweck ausgedrückt werden. Im Gegensatz zu pseudo-inkorporierten Nomen sind KO typischerweise determiniert und modifiziert, wie im folgenden Abschnitt gezeigt wird.

\subsection{Modifikation und Determination kognater Objekte}

Modifikation ist ein typisches Merkmal von KO. ${ }^{98}$ Die semantische Leistung der Modifikation und die Frage nach ihrer Notwendigkeit hängen stark von der Art der Determination ab. Daher werden beide Bereiche parallel diskutiert. Mit der Modifikation wird begonnen.

Sprecher und Schreiber schöpfen bei KO-Äußerungen die Möglichkeiten der Nominalmodifikation voll aus. Formal handelt es sich dabei um Adjektivattribute (22a), Genitivattribute (22b), Relativsätze (22c), Präpositionalattribute (22d) und aus dem Bereich der Wortbildung um Komposita (22e) und sogenannte Phrasenkomposita (22f).

(22) a. Romani Rose lächelt ein schiefes Lächeln. ${ }^{99}$

b. Willke lächelte das Lächeln der Eingeweihten. ${ }^{100}$

c. Entspannt saß Ron Sommer beim Abendessen mit Journalisten lächelte das Lächeln, das manche für arrogant halten. ${ }^{101}$

d. Andächtig setzt er sich in einen Klappsessel und lächelt ein Lächeln zwischen Wehmut, Stolz und Hoffnung. ${ }^{102}$

e. Sie stellt sich ans Pult und lächelt ihr Mädchenlächeln, bezaubernd und ausdauernd. ${ }^{103}$

f. Da lächelt Fischer sein Ich-bin-schon-mit-Milosevic-und-Rumsfeld-fertiggeworden-Lächeln. ${ }^{104}$

98 Dies wird in allen neueren Untersuchungen explizit erwähnt, z. B. bei Kuno \& Takami (2004: 128-130), Höche (2009: 209), Winkler (2009: 132f.), Sailer (2010: 194). In älteren Grammatiken wie bei Brugmann (1903) und Paul (1919) wird die Modifikation von KO gar nicht erwähnt. Behaghel (1923: 715f.) sieht die typische Modifikation der KO als neuhochdeutsches Phänomen, was sich mit Ruges (2015: 418) historischer Analyse deckt.

99 die tageszeitung, 23.10.2010, S. 20.

100 Braunschweiger Zeitung, 08.03.2007.

101 Süddeutsche Zeitung, 29.05.2002, S. 3.

102 die tageszeitung, 24.11.2005.

103 Berliner Zeitung, 14.06.2004.

104 Süddeutsche Zeitung, 10.12.2005. 
Häufig wird ein KO durch mehrere der aufgeführten Möglichkeiten zugleich modifiziert. Es darf angenommen werden, dass jene genutzte Vielfalt an nominalen Modifikationsmöglichkeiten unter synchroner Perspektive den KO-Gebrauch zusätzlich motiviert. Quantitativ fallen Adjektivattribute auf. Von den 505 Belegen mit Lächeln lächeln werden 462 durch ein oder mehrere Adjektive modifiziert. Zwei Muster sind besonders häufig. Die NP wird 228 Mal von einem Possessivartikel und $126 \mathrm{Mal}$ vom Indefinitartikel determiniert. Seltener, nämlich $15 \mathrm{Mal}$ wird das durch ein Adjektiv modifizierte KO durch den Demonstrativartikel und nur 7 Mal durch den definiten Artikel determiniert. Definite Artikel und Demonstrativartikel werden hauptsächlich dann gebraucht, wenn das Nomen durch einen Relativsatz oder eine Genitiv-NP modifiziert wird.

Das Adjektivattribut bestimmt die Art des Lächelns und damit häufig - wie unter 2.2 besprochen - die jeweilige Lesart als Vorgang oder aber Objekt. Der Determinator legt die Referenzweise fest. Der Indefinitartikel überführt das nominale Prädikat in einen Ausdruck, der auf einen beliebigen Vertreter der Art verweist, welche von der Verbindung aus Adjektiv und Nomen ausgedrückt wird. Hingegen führen definite Artikel wie der Possessivartikel zur Referenz auf ein singuläres Denotat. Der definite Artikel kann anaphorisch oder kataphorisch gebraucht werden. Häufig erlauben Relativsätze (22c) oder eine Genitiv-NP (22b) als Postmodifikation (kataphorisch) die Individuierung.

Im Falle der Possessivartikel wird jenes singuläre Denotat durch Bezugnahme auf den Possessor der Entität hergestellt. Wenn das Nomen auch über die Vorgangslesart verfügt, so kann jener Possessor als Agens verstanden werden. In diesem Falle kommt es, wie Höche (2009: 207) schreibt, zu einer konzeptuellen Überschneidung zwischen Agens und Verb auf der einen Seite und Possessivartikel und KO auf der anderen Seite. Denn in einer Äußerung wie (23a,b) ist der Possessor korreferent mit dem Agens des Verbs.

(23) a. Christine Bergmann, seit wenigen Wochen 72 Jahre alt, lächelt ihr mädchenhaftes Lächeln. ${ }^{105}$

b. Tobi lächelt wieder sein Bierkastengrübchen-Lächeln. ${ }^{106}$

c. Rudi Völler strich sich genüsslich durch die Silbertolle und lächelte das Lächeln des Triumphators. ${ }^{107}$

105 FOCUS, 24.10.2011, S. 68.

106 Caroline Mohr: Küssen kostet extra. Rowohlt, 2017.

107 Hamburger Morgenpost, 10.04.2006, S. 4. 
Die Belege in (23) werden primär generisch verstanden. ${ }^{108}$ Es handelt sich um bestimmte Typen von Lächeln, welche durch entsprechende Instanzen bzw. Exemplare realisiert werden. Hierauf gehen meinem Wissen nach nur Höche (2009: 205-208) und Sailer (2010: 196) explizit ein. In (23a) ist von dem mädchenhaften Lächeln (Unterart von Lächeln) die Rede, welches für sie typisch ist bzw. von ihrer Art dieses mädchenhaften Lächelns. Dies ist besonders dann der Fall, wenn das Nomen und der Modifikator einen kulturell etablierten Typ bezeichnen wie den guten Kampf kämpfen oder den Heldentod sterben und diese mit Possessivartikel gebraucht werden seinen guten Kampf kämpfen bzw. seinen Heldentod sterben. Ist das so wie in (23b) nicht der Fall, wird das Bierkastengrübchen-Lächeln ad hoc als eine Unterart von Lächeln verstanden, ${ }^{109}$ welche typisch für Tobi ist. In (23c) kann das Lächeln der Art entsprechen, wie der Triumphator es typischerweise lächelt. Der Eigenname referiert singulär. Daher gibt es keine Referenzidentität zwischen Völler und der generischen Lesart von Triumphator. Völler kann also als Instanz des Typs Triumphator verstanden werden.

Mitunter wird jene generische Lesart explizit ausgedrückt wie in (24a) durch Possessivartikel und typisch als Modifikator, in (24b) durch eine weder ana- noch kataphorisch gebrauchte definite NP und in (24c) durch eine Art RepertoireKonstruktion.

(24) a. Roger Schmidt bedankte sich und lächelte sein typisches Lächeln. ${ }^{110}$ (=die Art von Lächeln, welche für ihn typisch ist)

b. Kuhn-Piëch, Pferdeschwanz, graues Kostüm, flache Schuhe, lächelt das undurchdringliche Lächeln. ${ }^{111}$ (=ad hoc Annahme, dass es diesen Typ gibt, insbesondere als effiziertes Objekt)

c. Aber A. D. lächelte von allen seinen Lächeln das Verschmitzteste. ${ }^{112}$

Besonders interessant sind die Fälle, in denen nur eine generische Lesart möglich ist. Das ist dann der Fall, wenn der Possessivartikel (25a) oder das Erstglied des Kompositums (25b) nicht mit dem Subjekt koreferent sind. Krifka et al. (1995: 103)

108 Nach Krifka et al. (1995: 4) handelt es sich um definite Generizität im Gegensatz zur indefiniten. Den Autoren (ebd.: 103) zufolge referieren u. a. substantivierte Infinitive in diesem Fall auf einen Ereignistyp, dessen Realisierung die Ereignisse aus der indefiniten Lesart sind.

109 Krifka et al. (1996: 11, 63) verweisen darauf, das die generische Lesart auf etablierten Arten beruht. Im Falle substantivierter Infinitive schreiben sie (ebd.: 103f.) jedoch von produktiver Arten- oder besser Konzeptbildung.

110 Süddeutsche Zeitung, 29.08.2014, S. 35.

111 Süddeutsche Zeitung, 06.05.2015, S. 17.

112 Die Zeit, 01.01.1960, S. 29. 
bezeichnen jenen Konflikt als „arbitrary control“ und halten ihn für einen Auslöser der generischen Lesart bei deverbalen Nomen.

(25) a. Sie kneift die Augen suchend zusammen und lächelt mein Lächeln. ${ }^{113}$

b. „Ich würde sie gerne mal vertreten, und keiner merkt es“, sagt Knoll und lächelt ein Merkel-Lächeln. ${ }^{114}$

Wenn es sich um eine indefinite NP wie in (25b) handelt, dann besteht Referenz auf einen beliebigen Vertreter des Typs „Merkel-Lächeln“. Dies entspricht in etwa dem, was Dowty (1979: 69, 186) „creation of a performance object“ nennt. Das Hervorgebrachte ist eine Repräsentation des Denotats der NP. Somit gleichen sich „ein Merkel-Lächeln lächeln“ und „einen Tanz tanzen“, soweit es sich bei dem Tanz um ein etabliertes Muster handelt, welches reproduziert wird.

Handelt es sich hingegen um eine defintite NP wie in (25a), dann realisiert sie einen Typ bzw. eine Art. Dies ist relevant, weil es die Lesart der gesamten VP beeinflusst. Da es sich bei KO um effizierte Objekte oder Vorgänge handelt, sollte angenommen werden, dass jedes Objekt und jeder Vorgang nur ein einziges Mal hervorgebracht werden kann. Es finden sich nun aber Belege mit immer (26a mit dem Relativpronomen als KO) und oft (26b) zusammen mit definiter KO-NP. ${ }^{115}$

(26) a. Er lächelt dieses Lächeln, das er immer gelächelt hat und das immer alle als Beweis für eine gewisse Überheblichkeit gewertet haben. ${ }^{116}$

b. Sein feines Lächeln lächelt er oft während seines Auftritts. ${ }^{117}$

Offensichtlich kann sich das wiederholte Hervorbringen der definiten NP nur auf den jeweiligen Typ, nicht auf ein konkretes Objekt beziehen. Krifka (1989: 198, 213) bemerkt diesbezüglich, dass verba efficiendi sowohl auf Typen als auch auf konkrete Objekte bezogen werden können und daher eine grundsätzliche Ambiguität zwischen type- und token-Lesart bestehe. Die generische Lesart erklärt nun, dass ein Typ (durch eine unspezifische Zahl seiner Vertreter) anders als ein konkretes Objekt mehrfach hervorgebracht werden kann. Hierauf wird noch einmal bei der Analyse der Zeitkonstitution in KO-Ausdrücken in 4.2 eingegangen. An dieser Stelle sei festgehalten, dass jene Ambiguität besonders groß ist, wenn es sich um eine definite NP handelt, die nicht ana- oder kataphorisch gebraucht

113 Sally Koslow: Ich, Molly Marx, kürzlich verstorben. Freundinnen wie diese. dtv, 2016.

114 Berliner Zeitung, 07.09.2007.

115 Krifka et al. (1995: 7, 9) bezeichnen sie als Indikatoren für eine generische Lesart.

116 Süddeutsche Zeitung, 25.09.2013, S. 2.

117 Süddeutsche Zeitung, 29.12.2012, S. 8. 
wird. Zwingend wird ein generisches Verständnis bei einem Konflikt zwischen Subjekt und Possessivartikel bzw. Genitiv-NP mit Agenslesart. Diese Einschränkung ist wichtig, denn durch die Genitiv-NP kann auch der Grund oder die Art des Lächelns ausgedrückt werden wie in das Lächeln der Zuversicht lächeln. Auch in diesem Fall ist die primäre Lesart eine generische. Verschiedene Menschen können das Lächeln der Zuversicht lächeln, es kann auch immer wieder gelächelt werden.

Nun wird der Frage nachgegangen, inwieweit Modifikation notwendig ist. Pustejovski (2000: 68) hält sie für obligatorisch. Felser \& Wanner (2001: 111) werten die Modifikation des KO als Bedingung für dessen Akzeptabilität. Denn erst durch die Modifikatoren werde das „spell out“ des KO durch entsprechendes Plus an Bedeutung ausgelöst. Macfarland (1995: 12-14) hält Modifikatoren für nicht obligatorisch und begründet ihren Gebrauch pragmatisch. Unter den 505 Belegen von Lächeln lächeln im DeReKo, Komposita ausgenommen, sind siebzehn Äußerungen ohne Modifikator im engeren Sinne und zwar zwei mit Demonstrativartikel (27a), vierzehn mit Possessivartikel (27b) und einer mit Indefinitartikel (27c).

(27) a. Am Ende schütteln unsere Väter dann jedes Mal ihre graumelierten Köpfe und lächeln dieses Lächeln. ${ }^{118}$

b. Köhler lächelte sein Lächeln. ${ }^{119}$

c. Dann war ihr Mund wieder sein Mund und sie lächelten ein Lächeln. ${ }^{120}$

In (27a) wird das KO anaphorisch gebraucht. Es verweist auf das Antezedens dieses verschmitzte, auf merkwürdige Art weise wirkende Lächeln im vorvorhergehenden Satz. In (27b) bringt der Possessivartikel das Informationsplus. Er referiert auf das Subjekt und löst die Typ-Lesart aus, nämlich das Köhler-Lächeln, das für Köhler typische Lächeln. Durch den Kontext kann (27c) neben der indefiniten Lesart auch in Numerallesart verstanden werden, nämlich im Sinne von einem einzigen und daher gemeinsamen Lächeln. Somit gibt es selbst bei unmodifizierten KO das angesprochene Informationsplus. Wenn auch Modifikation im formal-grammatischen Sinne nicht obligatorisch $\mathrm{zu}$ sein scheint, so müssen KO spezifiziert werden. Jene Spezifizierung kann prädikativ oder attributiv sein, aber auch text- oder situationsdeiktisch. Das nötige Informationsplus ist semantisch-pragmatisch motiviert. Es geht um die Vermeidung von Tautologie.

118 die tageszeitung, 17.06.2008, S. 11.

119 Braunschweiger Zeitung, 21.09.2005.

120 Martin Walser: Die Verteidigung der Kindheit. Frankfurt a. M., 1991, S. 136. 
Hierin liegt auch ein Indiz für die Nicht-Kompositionalität der elementaren KOArgument-Konstruktion. ${ }^{121}$

Abschließend geht es um die gerade angesprochene Quantifizierung nämlich durch quantifizierende Determinatoren (28a) und sogenannte Numerativkonstruktionen (28b).

(28) a. Dann hast Du im Leben alles gemacht und jedes Lachen gelacht. ${ }^{122}$

b. Bei Frauen, die täglich neun bis zehn Stunden Schlaf schlafen, lag das Risiko indes 38 Prozent über dem Durchschnitt. ${ }^{123}$

Die durch den Quantifikator jedes determinierte NP jedes Lachen verweist auf den gesamten Denotatsbereich des nominalen Prädikats. Insbesondere bei Verbalabstrakta ist (wie typischerweise bei Massennomen) jedoch auch eine generische Lesart möglich. Diese wird umso mehr ausgelöst, da es sich bei KO um effizierte Objekte handelt. Wer jedes Lachen gelacht hat, der hat Instanzen bzw. Exemplare aller möglichen Sorten von Lachen hervorgebracht. In jener sortalen Lesart liegt das Bedeutungsplus trotz fehlender Modifikation im engeren Sinne.

Verbalabstrakta wie Schlaf sind normalerweise nicht zählbar, da sie ungequantelt sind. Nun können jedoch modifizierende Maßausdrücke wie Stunde mit einem Numeral wie neun bis zehn Stunden wie in (28b) mit einem Verbalabstraktum kombiniert werden. Krifka (1989: 4, 61-64) spricht von Numerativkonstruktionen, welche zur Quantelung der gesamten NP führen (vgl. 2.2). Die Modifikation mittels Quantifikation führt somit zu einer Veränderung der Referenzweise, worum es noch einmal unter 4.2 geht, wenn die Zeitkonstitution der gesamten VP analysiert wird.

Bevor im folgenden Kapitel verschiedene Analysevorschläge diskutiert werden, seien die wesentlichen Beobachtungen dieses Abschnitts zusammengefasst. KO werden typischerweise modifiziert. Dabei werden alle Möglichkeiten nominaler Modifikation genutzt. Im Zusammenhang mit der Art der Determination wurden zwei Lesarten unterschieden. Definite KO referieren häufig generisch auf einen Ereignis- oder Objekttyp. Besonders auffällig ist die Determination mittels eines Possessivartikels, welcher mit dem Subjekt koreferent ist. Zwischen Agens und Verb (er lächelt) sowie Nomen mit Vorgangslesart und Possessivartikel (sein Lächeln) besteht eine konzeptuelle Überschneidung. Die Typenlesart wurde als informatives Plus gewertet. Besteht entsprechende Koreferenz nicht, so ist nur

121 Für diesen Hinweis danke ich einem Gutachter.

122 https://www.spruchfeder.de/sprueche-zum-leben/

$123 \mathrm{http} / /$ www.spektrum.de/news/zu-viel-und-zu-wenig-schlaf-erhoehen-risiko-fuer-herzkreislauf-erkrankungen/614798 
die generische Lesart möglich. Ist die KO-NP indefinit, so kann sie auf ein beliebiges Objekt bzw. ein beliebiges Ereignis verweisen, welches im Denotatsbereich des nominalen Prädikats liegt. Jene Ereignisse oder Objekte können, müssen aber nicht Instanzen eines Typs sein. Ist dies der Fall, so wird durch ihren Ausdruck der jeweilige Denotatstyp erschaffen oder es handelt sich um das Hervorbringen einer Repräsentation, einer Kopie des jeweiligen Typs.

\section{Analysen}

Im Folgenden werden bestehende Analysen der KO diskutiert. Unter 3.1 geht es um die (klassische) Frage, ob es sich bei KO um Adjunkte oder Argumente handelt. Im Anschluss wird in 3.2 untersucht, ob KO, so wie es Macfarland (1995) und Felser \& Wanner (2001) vorschlagen, funktional als ,Telisierer', d.h. als „aspectual theme“-Argument analysiert werden sollten. Unter 3.3 werden konstruktionsgrammatische Analysen von Winkler (2009, 2015) und Höche (2009) und unter 3.4 die HPSG-Analyse von Sailer (2010) diskutiert.

\subsection{Kognate Objekte: Argument oder Adjunkt?}

In allen Fällen, in denen das KO nicht vom Verb lizenziert wird, stellt sich die Frage nach dem syntaktischen und semantischen Status. Winkler (2009) analysiert genauso wie Brugmann (1903: 441 f., § 561.2b), Helbig (1973: 61) und Bausewein (1990: 74) KO als Objekte. Heidolph, Flämig \& Motsch (1981: 335) zählen sie zu den Objekten, grenzen sie aber von effizierten Objekten ab. Denn sie würden „nur den Vollzug des Vorgangs selbst, eine seiner Phasen oder eine spezifische Art seines Vollzugs“ bezeichnen. Paul (1919: 226) behandelt kognate Objekte unter den freieren, aber objektnahen Akkusativverwendungen. Helbig \& Buscha (2001: 262) schreiben von „inneren Objekten“, klassifizieren sie aber unter den lexikalischen Prädikatsteilen. In der Dudengrammatik (2016: 814, § 1240) werden „innere Objekte“ unter den Akkusativobjekten erwähnt, allerdings mit dem Zusatz, dass keine Einigkeit darin bestehe, ob es sich um eine Ergänzung oder um eine Angabe handele. Für das Englische sieht die Diskussion ähnlich aus.

Seit Jones (1988), der KO im Rahmen der Theta-Theorie ${ }^{124}$ analysiert hat, gelten folgende Eigenschaften der KO als Indizien für deren Adjunktstatus. KO

124 Jones (ebd.: 104) nimmt an, dass KO auf der Tiefenebene kasuslos seien, weil sie keine Theta-Rolle haben. Der Akkusativ werde ihnen als unmarkierter Kasus auf der phonologischen 
seien nicht passivierbar (andernfalls seien es reguläre Objekte (ebd.: 91)). Sie würden nicht mit unakkusativischen Verben vorkommen. Sie müssten modifiziert und könnten nicht pronominalisiert werden. Sie seien nicht erfragbar und nicht topikalisierbar. ${ }^{125}$

Diese Annahmen sind für das Englische (u.a. Macfarland 1995, Kuno \& Takami 2004) und für das Deutsche (Paul 1919, Winkler 2009) empirisch nicht haltbar. Äußerungen mit KO werden unabhängig von der Lesart und Form der kognaten NP passiviert gebraucht. Dies trifft für die changierende Objekt- und (wenn auch viel seltener) die Vorgangslesart zu (29a), in beiden Fällen auch, wenn es sich um eine generische Lesart (29b) handelt. KO werden topikalisiert (29c), sie können pronominal realisiert (29d) und anaphorisch durch ein Pronomen wieder aufgegriffen werden (29e).

(29) a. Da wird ein betörendes Lächeln gelächelt, Jünglinge wandeln auf dem Pfad der Wahrheit und die Fäden des Schicksals verknüpfen sich unauflöslich. ${ }^{126}$

b. Während bei uns der nächtliche Schlaf der Gerechten geschlafen wird, ist es in der Isidis-Ebene früher Nachmittag. ${ }^{127}$

c. Sein feines Lächeln lächelt er oft während seines Auftritts [...] $]^{128}$

d. Isolde [...] sang ihren Liebestod verklärt und innig: aber sie starb ihn nicht $[. . .]^{129}$

e. das schwein hätte lieber sein leben gelebt, es wurde ihm ungefragt genommen. ${ }^{130}$

Die in (29) dargestellten Eigenschaften sind klare Indizien für den formalen Objektstatus von KO. Zu beachten ist, dass die Pronominalisierung durch die Relation des Hervorbringens eingeschränkt ist. Denn ein Ereignis oder Objekt kann nur einmal hervorgebracht werden. Lächelt jemand ein schönes Lächeln, so kann es ein anderer nur lächeln, wenn es generisch, also als Typ verstanden wird. ${ }^{131}$

Ebene zugewiesen. Somit verändert Jones den Chomsky'schen Kasusfilter, demzufolge zuerst Kasus und danach Theta-Rollen vergeben werden.

125 Eine tabellarische Übersicht jener Annahmen findet sich in Massam (1990: 163f.).

126 Falter, 10.07.2002, S. 51; Tito lebt.

127 Der Spiegel (Online), 23.12.2003.

128 Süddeutsche Zeitung, 29.12.2012, S. 8.

129 Süddeutsche Zeitung, 27.07.1993, S. 9.

$130 \mathrm{https} / /$ bazonline.ch/leben/essen-und-trinken/Blutwurst-macht-man-mit-viel-Gefuehl/ story/28381914

131 Daher wird Real Puigdollers’ (2008: 161) Erklärung abgelehnt, dass „„Maggie smiled a silly smile and then her brother smiled it" nicht möglich sei, da es sich bei dem Nomen smile um Ereignislesart handele. 
Die Erfragbarkeit einer Entität kann nur als Test für die verbale Lizenzierung als Default-Argument derselben gelten. Denn von einem Verb aus kann nur erfragt werden, was dieses typischerweise präsupponiert. Auch hierin unterscheiden sich die effizierenden transitiven Verben von den Verben, welche erst als Instanzen der Konstruktion mit einem KO gebraucht werden können. Am Status als Argument ändert das nichts.

Ein weiteres wesentliches Argument gegen den Adjunktstatus ist, dass KO bei affizierenden transitiven Verben deren ursprüngliches Objekt blockieren (30). Im Englischen verweist Massam (1990: 166) explizit hierauf.

(30) a. Der Pflaumenbaum, unter dem Niedecken seinen ersten Kuss küsste, ist gefällt $[. . .]^{132}$

b. ^Der Pflaumenbaum, unter dem Niedecken seinen ersten Kuss seine Freundin küsste, ist gefällt.

In Bezug auf die Semantik analysieren Jones (1988: 89, 93) und später auch Moltmann (1989: 300) KO als Adjunkte. Sie würden nicht auf Entitäten referieren, sondern über dem vom Verb bezeichneten Ereignis gleich einem Adverbial prädizieren. Heidolph, Flämig \& Motsch (1981: 340) schreiben, die KO „berühren sich mit den modalen Adverbialbestimmungen und nehmen die mit diesen verbundene semantische Rolle wahr. Das gilt zumindest für solche Objekte, die nicht auf Gegenstände referieren.“ Unter 2.2 wurde der Entitätsbegriff auf Ereignisse, Relationen etc. ausgedehnt. Somit beinhaltet die Referenz auf Entitäten sowohl ,Dinge، als auch hypostasierte Ereignisse. Das Augenmerk liegt hier auf Gegenständen der Rede, also auf sprachlichen (nicht ontologischen) ,Dingen“. Maienborn schreibt diesbezüglich (2011: 806) „events are things in the real world like objects; they can be counted, they can be anaphorically referred to, they can be located in space and time, they can be ascribed further properties." (Kursiv im Original). Im vorherigen Abschnitt wurde die Determiniertheit der KO - im Gegensatz zu inkorporierten Prädikatsteilen - mit ihrer Referentialität, sei es in Bezug auf Dinge oder Ereignisse, auf Konkreta oder Typen, erklärt. Allerdings muss nun die scheinbare Umformung eines KO-Ausdrucks (31a) in einen adverbialen Ausdruck (31b) betrachtet werden. Vor einem gänzlich anderen theoretischen Hintergrund berufen sich Jones (1988: 93) und Sailer (2010: 197) auf angebliche Bedeutungsgleichheit beider Äußerungen.

132 Süddeutsche Zeitung, 04.09.2013, S. 31. 
(31) a. Er lächelt ein schüchternes Lächeln.

b. Er lächelt schüchtern.

Was den Wahrheitswert betrifft, so ist dieser für (31a) und (31b) gleich. Denn die Aussagen in (31) sind, bezogen auf ein außersprachliches Ereignis, beide wahr oder beide falsch. Dies ist eine, wie Welke (2016: 72) schreibt, „in modernen Grammatiken übliche extensionale [...] Bedeutungsauffassung“. Die adverbiale Deutung des KO in (31a) lässt sich nur nachvollziehen, wenn (31b) für die zugrunde liegende Struktur gehalten wird. Ein Argument dagegen ist, hierauf weist u.a. Horita (1996: 224) hin, dass Umformungen nicht immer möglich sind. ${ }^{133}$ So lässt sich z. B. (32a) nicht in (32b) umformen.

(32) a. Du hast ja meine Nummer”, sagte sie, und sie lächelte ein kleines Lächeln. ${ }^{134}$

b. `Du hast ja meine Nummer”, sagte sie, und sie lächelte klein.

Dies ist verständlich, da das Dimensionsadjektiv die Objektlesart des Nomens bestimmt und damit nicht adverbial auf das Verb übertragen werden kann. Doch selbst in Fällen, in denen dies möglich ist (ein breites Lächeln lächeln - breit lächeln), besteht eine wesentliche Differenz zu den adverbialen Alternativen. Diese liegt in der Argumenthaftigkeit der KO innerhalb der Relation des Hervorbringens. Dies wird besonders deutlich, wenn wir KO-Konstruktionen (33a) mit entsprechenden appositiven Fügungen (33b) vergleichen. ${ }^{135}$ Letztere zeichnen sich nicht nur durch eine Sprechpause bzw. ein Komma aus. Wesentlich ist die Kasusmarkierung. Das KO in (33a) steht im Akkusativ, die appositive NP in (33b) im Nominativ.

133 Höche (2009: 220-228) führt bzgl. der Verben live, die, smile mit KO im Gegensatz zu entsprechenden Adverbkonstruktionen eine „distinctive collexeme analysis“ durch. Neben einzelnen klar präferierten (entrenched) Mustern, alternieren die Ausdrucksvarianten ohne signifikante Unterschiede.

134 Süddeutsche Zeitung, 13.10.2003, S. 16.

135 Interessanterweise macht Jespersen (1924: 138) auf jene „kind of ,appositum““ aufmerksam und grenzt sie von $\mathrm{KO}$ ab, nachdem er schreibt, dass sich fight the good fight von fight well unterscheide. Worin jener Unterschied besteht, bleibt allerdings offen. 
(33) a. Schoder wurde sofort ins Krankenhaus eingeliefert, doch die Ärzte kämpften einen vergeblichen Kampf um sein Leben. ${ }^{136}$

b. Zwei Stunden lang hatten Notärzte um das Leben des Müncheners gekämpft, ein vergeblicher Kampf, wie sich herausstellen sollte. ${ }^{137}$

In beiden Fällen wäre unter denotativ-semantischer Perspektive eine Umformung in die adverbiale Konstruktion vergeblich kämpfen möglich. Wird jedoch die sprachliche Konstruktion des Ereignisses betrachtet und signifikativ-semantisch vorgegangen, dann ist dies nicht möglich. ${ }^{138}$ Denn in (33a) wird der vergebliche Kampf kämpfend hervorgebracht - unabhängig davon, ob Kampf eher in seiner Ereignis- oder Objektlesart verstanden wird. Die Argumenthaftigkeit des KO als effizierte Entität ist die semantische Seite der formalen Eigenschaften, die in (29) und (30) dargestellt wurden. Ähnlichkeiten und Unterschiede zwischen KO-Argumenten und entsprechenden Adjunkten zeigen sich formal und semantisch auch dann, wenn das KO-Nomen (34a) als Adjunkt-Phrase (34b) ausgedrückt wird.

(34) a. Marcello lächelt sein Mastroianni-Lächeln.

b. [...] Ulla Meinecke lächelt mit ihrem Ulla-Meinecke-Lächeln. ${ }^{139}$

Nicht nur die Adjunktanalyse wird der anhand von (33a) und (34a) besprochenen Argumenthaftigkeit der KO nicht gerecht. Moltmann (1989) und Mittwoch (1998) schlagen im Rahmen der Ereignissemantik vor, KO als ,overte‘ Realisierung des ansonsten ,versteckten' Ereignisarguments zu klassifizieren. ${ }^{140}$ Im sogenannten ,Post-Davidsonian turn“ werden Verben als einstellige Prädikate über den von ihnen ausgedrückten Ereignissen analysiert. Die klassischen Argumente werden anschließend als Ereignisbeteiligte (quasi als dessen Funktion) in verschiedenen Rollen eingeführt. Analog dazu werden auch Adjunkte eingeführt, allerdings nicht als thematische Rollen, sondern z.B. mit entsprechender Präposition als

136 Niederösterreichische Nachrichten, 23.01.2014.

137 Nürnberger Nachrichten, 30.07.2010, S. 3.

138 Ich beziehe mich auf Welkes (2005: 95-98) Begriffe ,signifikativ-“ vs. ,denotativ-semantischer Rollen'. Unter denotativ-semantischen Rollen werden Rollen verstanden, welche scheinbar von entsprechendem Sachverhalt an sich oder aber einer vorausgesetzten (grundlegenden) syntaktischen Struktur gewonnen werden. Signifikativ-semantische Rollen beziehen sich auf die sprachliche Konstruktion von Sachverhalten. Bei dem Fillmore'schen Satz The key opened the door wäre die denotativ-semantische Rolle von key ,Instrumental', die signifikativ-semantische ,Agens'.

139 Berliner Morgenpost, 10.04.2005.

140 Mittwoch (1998) bezieht sich allerdings primär auf das Hebräische. 
Prädikate über dem Ereignis-Argument. ${ }^{141}$ Dies wird, nach Mittwochs (1998) Notation, für den Satz in (34b) wie folgt dargestellt.

(35) ヨe (lächeln (e) \& Actor (Ulla Meinecke, e) \& mit ihrem U.-M-Lächeln (e))

Die Repräsentation in (35) bildet ab, dass es ein Ereignis e gibt, welches ein Lächeln-Ereignis ist. Das Ereignis hat einen Mitspieler in der Rolle Agens, nämlich Ulla-Meinecke und das Ereignis (U. M. lächelt) geschieht mit ihrem U.M.-Lächeln. Problematisch wird nun aber die Analyse des KO in (33a). Als reinen Ausdruck des Ereignisarguments und somit ohne thematische Rolle werden die dargestellten semantischen und formalen Unterschiede zwischen (33a, 34a) auf der einen Seite und (33b, 34b) auf der anderen Seite nicht erfasst. Diese Unterschiede können nur dann adäquat erfasst werden, wenn KO als syntaktische und semantische Argumente analysiert werden. Daher stellt sich die Frage nach ihrer Lizenzierung. Denn die zentrale Domäne der KO sind, wie in 2.1 dargestellt, gerade die intransitiven activity-Verben.

Unter gebrauchsbasierter Perspektive sollte die Frage nach der Lizenzierung des KO differenzierter betrachtet werden. In Anlehnung an die KO-Analyse von Höche (2009) für das Englische bemerkt Winkler (2009: 128f.), dass eine kleine Gruppe von Verben wie leben, schlafen, kämpfen, träumen auffällig häufig mit einem KO gebraucht werden. Im Gegensatz dazu ließen sich viele Verben in den Korpora des IDS nur sehr selten mit KO belegen. Daher sollte die Gruppe der intransitiven Verben nicht über einen Kamm geschoren werden. Im DWDS-Korpus wird beispielsweise für lächeln mit Lächeln als KO eine Assoziationsstärke (logDice) von 10.44, bei schlafen und Schlaf von 9.31 berechnet. Bei grinsen und schmunzeln lässt sich von entsprechenden Verbindungen gar nicht von Kollokationen sprechen. Daher sollte je nach Assoziationsstärke davon ausgegangen werden, dass bestimmte Verben, die eigentlich intransitiv sind, dennoch ein KO als Argument selegieren. ${ }^{142}$ Die meisten, auch semantisch sehr ähnliche Verben tun dies nicht und werden ad hoc mit einem KO gebraucht. Bei diesen Verben ist zu klären, wodurch $\mathrm{KO}$ als Argumente lizenziert werden.

141 Im Gegensatz dazu bestimmte Davidson (nur bei accomplishment-Verben) das Ereignisargument als zusätzliches Argument neben den klassischen Ergänzungen. Cf. Maienborn (2011: 811) und Mittwoch (1998: 318).

142 Praktischen Niederschlag findet diese Tatsache z.B. im Elektronischen Valenzwörterbuch deutscher Verben (E-VALBU), wo unter lächeln im Gegensatz zu grinsen eine NP im Akkusativ als kognates Objekt vermerkt ist. http://hypermedia.ids-mannheim.de/evalbu/index.html 


\subsection{Kognate Objekte als Telisierer?}

Macfarland (1995) und Felser \& Wanner (2001) analysieren KO genauso wie Massam (1990) als Resultatsobjekt. Felser \& Wanner (2001: 110 f.) bestimmen das KO als „product, or outcome, of the action of V-ing“. Bezüglich der Lizenzierung gehen sie (ebd.: 106f.) davon aus, das alle intransitiven activity-Verben eigentlich und primär (!) transitiv sind. ${ }^{143}$ Dadurch könne die lexikalische Repräsentation direkt in die Syntax überführt und das KO regulär als Akkusativobjekt ausgedrückt werden. De facto erinnert dies an Engelberg (2000: 125), der alle KO für lexikalisch lizenziert hält. ${ }^{144}$ Würde jedoch jeder transitive Gebrauch eines eigentlich intransitiven Verbs gleichermaßen auf einen entsprechenden Eintrag im verbalen Selektionsrahmen zurückgeführt werden, so wäre das Konzept lexikalischer Lizenzierung entwertet. Die Nicht-Erfragbarkeit der nicht verbal lizenzierten KO wäre bei dieser Annahme genauso schwer zu erklären wie die häufigen seltenen Belege und Einmalbelege. ${ }^{145}$

Wenn alle eigentlich intransitiven (unergativen) Verben transitiv sind, muss der Gebrauch von KO nur funktional motiviert werden. Felser \& Wanner (2001: 109) beschreiben es nach Dowty als „incremental theme“. Dowty (1991: 567f.) versteht hierunter ein Patiens, an dessen Zustand sich sukzessive die Phasen der Handlung ablesen lassen. Effizierte und zerstörte bzw. konsumierte Objekte zählen somit zu typischen inkrementellen Objekten. KO wiederum sind effizierte Objekte. Da die Aktion des Hervorbringens mit dem Hervorgebrachten endet,

143 Dies erinnert an die sogenannte ,Burzio’s Generalization‘. Burzio (1986: 165) behauptet im Rahmen der Rektions- und Bindungstheorie, dass alle Verben, welche ihrem Subjekt eine Theta-Rolle zuweisen, einem Objekt auch den Akkusativ zuweisen können. Auf diese Weise soll auch erklärt werden, warum unakkusativische Verben von Resultativkonstruktionen und KO ausgeschlossen seien. Dass jedoch auch unakkusativische Verben mit KO gebraucht werden, wurde in 2.1 dargestellt.

144 Engelberg (ebd.) begründet dies allerdings damit, dass nicht alle Verben mit einem KO gebraucht werden können. Unter 2.1 wurde seine Annahme durch empirische Gegenbelege als zu restriktiv abgelehnt.

145 Einen scheinbaren Ausweg stellt die Analyse von Levin \& Rappaport (1988: 281f.) dar. Sie schlagen eine lexikalische Regel vor, welche die Bedeutung von activity-Verben um eine resultative Komponente erweitert. Entsprechende Verben werden um einen CAUSE und BECOMEOperator erweitert, deren Argumente dann in die Syntax überführt würden. Problematisch ist, dass die hoch abstrakte Regel nicht die typische ,Kognatheit‘ entsprechender Objekte erfasst. Zudem würden KO- und Resultativkonstruktionen durch die gleiche Regel lizenziert. Dies wird wesentlichen Form-Funktions-Zusammenhängen nicht gerecht. Bei Resultativkonstruktionen (jdn. tot schießen) ist das im Akkusativ kodierte Argument ein affiziertes Objekt, das Resultat wird durch eine prädikative AP ausgedrückt. Bei KO (einen Schuss schießen) ist das im Akkusativ kodierte Argument ein effiziertes Argument und damit selbst das Resultat. 
bestimmen Felser \& Wanner (2001: 110) wie zuvor Macfarland (1995: 145f.) und später Horrocks \& Stavrou (2010: 297) die Funktion der KO als Telisierer und nennen es „aspectual theme“.

Die Idee dahinter ist einleuchtend. Sie findet sich bereits bei Jacobsohn (1933: 297), der schreibt: „[D]er Accusativus effectivus macht das Verb perfektiv.“ Hierunter versteht er, dass das Geschehen nicht kontinuierlich in der Zeit verläuft, sondern einen Endpunkt aufweist. Dies entspricht der Bestimmung einer Handlung als telisch durch Garey (1957: 106): ,an action tending towards a goal“. Bezogen auf Äußerungen mit KO wäre zu erwarten, dass die Handlung durch das Hervorbringen einer Entität begrenzt (gequantelt), also telisch ist. Ist das effizierte Objekt da, so endet die Handlung. In diesem Sinne begrenzen (quanteln) die KO die VP, zu der sie gehören. Dies lässt sich anhand der klassischen Tests demonstrieren. ${ }^{146}$ Während der intransitive Gebrauch von „tanzen“ ein Ereignis atelisch konstruiert (36), führt der Gebrauch mit einem KO zur Darstellung eines telischen Ereignisses (37).

(36) a. Anna tanzte stundenlang. - vs. *Anna tanzte in einer Stunde.

b. Wenn Anna dabei ist zu tanzen, dann wird sie auch getanzt haben.

(37) a. Anna tanzte ihren letzten Tanz in fünf Minuten. - vs. *Anna tanzte stundenlang ihren letzten Tanz. (außer iterativ den letzten Tanz wiederholt tanzen und partitiv an dem letzten Tanz tanzen)

b. Wenn Anna dabei ist, ihren letzten Tanz zu tanzen, *dann wird sie ihren letzten Tanz getanzt haben.

Mereologisch ausgedrückt, fällt ein Teil von ,Anna tanzt' in (36) ebenfalls unter ,Anna tanzt' und zwei Ereignisse, die ausdrücken, dass ,Anna tanzt' fallen auch wieder unter ,Anna tanzt‘ (Kumulativität). Im Gegensatz dazu fällt ein Teil von ,Anna tanzt ihren letzten Tanz‘ (37) nicht unter ,Anna tanzt ihren letzten Tanz und zwei Ereignisse, die ausdrücken, dass ,Anna ihren letzten Tanz tanzt‘, fallen nicht unter das gleiche Prädikat, sondern unter ,Anna tanzt ihre beiden letzten Tänze‘ (Quantelung).

Bei vielen Äußerungen mit KO ergeben jene Tests jedoch gerade keine klaren Ergebnisse oder negative Evidenz (38), worauf auch de Swart (2007: 42f.) und indirekt Höche (2009: 193), Real Puigdollers (2008: 161) sowie Sailer (2010: 198) hinweisen.

146 Cf. Vendler (1957: 145) und Dowty (1979: 60). 
(38) a. ?Anna schlief in fünf Minuten einen tiefen Schlaf. - vs. Anna schlief stundenlang einen tiefen Schlaf.

b. Wenn Anna dabei ist, einen tiefen Schlaf zu schlafen, ?dann wird sie einen tiefen Schlaf geschlafen haben.

Offensichtlich führen KO nicht automatisch $\mathrm{zu}$ einer Telisierung der beschriebenen Situation. Woran das liegt, wird in 4.2 dargelegt. An dieser Stelle sei nur festgehalten, dass eine funktionale Lizenzierung der $\mathrm{KO}$ als „aspectual theme“ nicht möglich ist. Dies stellt jedoch nicht die Argumenthaftigkeit der KO in Frage und auch nicht die Tatsache, dass ein effiziertes Objekt eine Art Zielpunkt ist, auf welches die Ereignisbeschreibung hinausläuft.

\subsection{Konstruktionsgrammatische Analysen}

Im Folgenden werden zwei konstruktionsgrammatische Analysen der KO diskutiert, die von Waltraud Winkler $(2009,2015)$ für das Deutsche und die von Silke Höche (2009) für das Englische. Beide Autorinnen analysieren KO als Argumente von verschiedenen, miteinander verwandten Konstruktionen. Die Analysen basieren auf dem Goldberg'schen (1995: 43) Modell, wonach Verben mit Konstruktionen fusionieren und dabei ihre Partizipantenrollen auf die formal und semantisch spezifizierten Argumentstellen der Konstruktion abbilden und/oder durch die Konstruktion Argumente erhalten, die sie lexikalisch nicht lizenzieren. In diesem Fall werden Verb- und Konstruktionsbedeutung miteinander abgeglichen (coercion). Nach Goldberg (1995: 50) spielt dabei das semantische Kohärenzprinzip die wesentliche Rolle. Dieses besagt, dass die Rollen des Verbs und der Konstruktion semantisch kompatibel sein müssen. Eine Verbrolle muss als Instanz eines Arguments der Konstruktion abbildbar sein. Eine Konstruktionsrolle muss als Verbrolle konzeptualisierbar sein. Im Falle der KO bedeutet dies, dass die Verben ihr erstes Argument, typischerweise die Agensrolle, auf die Agensrolle der Konstruktion abbilden. Bei den intransitiven activity-Verben führt die Konstruktion ein zusätzliches Argument ein, nämlich das KO. Nun geht es darum, wie jenes zusätzliche Argument semantisch kodiert wird.

Sowohl Winkler (2015: 16) als auch Höche (2009: 141) differenzieren zwischen Objekt- und Ereignislesart des KO. Höche (ebd.) bindet jedoch nur bei transitiven effizierenden Verben wie build und weave die Objektlesart an die Konstruktion selbst. Bei intransitiven activity-Verben wie smile lässt sie offen, ob das KO als Objekt oder Ereignis bzw. Vorgang verstanden wird. In beiden Fällen beschreibt sie die KO als effizierte Objekte. 
Winkler (ebd.: 16) hingegen nimmt eine Konstruktion an, welche die Ereignislesart des KO festlegt. Als typische Vertreter werden u. a. einen harten Kampf kämpfen und ein schönes Lächeln lächeln aufgeführt. Unter 2.2 wurde gezeigt, dass die entsprechende Lesart stark von der Art der Nominalisierung abhängt und selbst bei Infinitivkonversionen innerhalb einer Äußerung mit KO changiert. Ebenso wurde gezeigt, dass die jeweilige Lesart häufig erst durch die Art der Modifikation bestimmt wird, nicht durch die Argumentkonstruktion selbst. ${ }^{147}$ Zudem besteht selbst bei Ereignislesart die Relation des Hervorbringens, was Winkler nicht erwähnt. Hierzu wurden im vorherigen Abschnitt appositive NP mit KO verglichen.

Höche (2009: 88f.) analysiert nun aber, wie bereits erwähnt, auch affizierte Objekte (to fish some fish) als Instanzen einer KO-Konstruktion. Dies wurde abgelehnt. Wird der Form-Funktions-Zusammenhang ernst genommen - die Konstruktionsgrammatik basiert auf dem Bilateralitätsprinzip - so kann nicht nachvollzogen werden, inwiefern Ausdrücke wie Fische fischen oder einen komischen Geruch riechen zur gleichen Klasse wie einen harten Kampf kämpfen oder ein Gewebe weben gehören sollen. Zwar wird in beiden Fällen das zweite Argument im Akkusativ ausgedrückt und bezeichnet ein Patiens. Aber nur im letzten Fall handelt es sich um ein effiziertes Patiens. Die stilistische Gemeinsamkeit wurde in 2.1 als figura etymologica erfasst.

Winkler (2015: 17-19) schlägt weitere, sehr detaillierte Konstruktionen vor. Speziell für das Verb sterben nimmt sie zwei Konstruktionen an, eine mit Akkusativobjekt und eine, in der das KO im Genitiv ausgedrückt wird (eines grausamen Todes sterben). Bei letzterer handelt es sich m. E. jedoch nicht um einen Vertreter von KO-Konstruktionen. Denn das KO verhält sich syntaktisch gerade nicht wie reguläre Objekte. Der Ausdruck mit Genitiv-NP zeigt eher den ursprünglichen Adjunktstatus, aus welchem sich, wie Handwerker (2010: 22) schreibt, ein „passivfähige[s] Objekt gemausert“ habe. In beiden Fällen begründet Winkler (2015: 17) die Eigenständigkeit der Konstruktionen damit, dass sterben als unakkusativisches Verb einen Sonderfall darstelle und das Nomen Tod nicht vom Verb abgeleitet ist. In 2.1 wurde gezeigt, dass und warum auch fallen und stürzen, in älteren Belegen auch wachsen mit KO gebraucht werden bzw. wurden. Unter 2.2 wurden verschiedene Fälle besprochen, in denen der nominale Kern des KO nicht vom Verb abgeleitet ist (ein Lächeln schmunzeln). Daher ist Winklers Begründung für diese an sterben gebundene eigenständige Konstruktion schwer nachvollziehbar. Viel eher sollte die Bindung der Konstruktion an das Verb mit ihrer Gebrauchshäufigkeit begründet werden. So wird im DWDS-Korpus zwischen

147 Ebenso Höche (2009: 83, 186-190) in ihrer Analyse für das Englische. 
sterben und Tod (als Akkusativobjekt) in etwa die gleiche Assoziationsstärke (logDice 9.62) berechnet wie für bauen und Haus (logDice 10.1). Entsprechende Assoziation liegt genauso bei den ähnlich kollokational gefestigten KO einen Heldentod, Märtyrertod sterben vor. Zudem ist zu beachten, dass trotz jener Bindung an das Verb eine gewisse Variation möglich ist (39).

(39) Die Welt krepierte einen langsamen, grauen Tod. ${ }^{148}$

Einen weiteren Konstruktionstyp schlägt Winkler (2015: $20 \mathrm{f}$.) zur Lizenzierung von einen Traum träumen, einen Glauben glauben vor. Das erste Argument bezeichne den Zustandsträger des verbalen Geschehens, das zweite den Inhalt jenes Zustands. Evidenz hierfür ist nach Winkler die Tatsache, dass das KO auch als komplexe Proposition ausgedrückt werden kann wie in er träumte, dass er sie wieder sehen würde. In ein schönes Leben leben ist das KO jedoch genauso wie bei einen schönen Traum träumen das Hervorgebrachte. Dass träumen anders als leben einen spezifischen Inhalt präsupponiert, dürfte den Ausdruck mit KO (Akkusativ des Inhalts!), also die Fusion mit einer KO-Konstruktion erleichtern bzw. $\mathrm{zu}$ entsprechendem Verbeintrag führen. ${ }^{149}$ Ein wesentlicher Unterschied besteht in der vom Verb festgelegten Rolle des ersten Arguments. Ein Traum kann bewusst und willentlich aber eben auch unbewusst und nicht kontrollierbar geträumt werden wie in einen furchtbaren Traum träumen. Jene Differenz zwischen prototypischem Agens und Experiencer ergibt sich jedoch aus der Verbbedeutung sowie der Modifikation des KO. Es ist nicht nachvollziehbar, warum dies durch die das KO lizenzierende Konstruktion festgelegt sein sollte.

Des Weiteren schlägt Winkler (2015: $21 \mathrm{f}$.) eine Konstruktion vor, in welcher das KO einen notwendigen Begleitumstand des verbalen Tuns ausdrückt. Instanzen dieser Konstruktion seien ein paar Tränen weinen und Rotz und Wasser heulen. Hier liefert das unter 2.1 angesprochene Merkmal ,Emission“ der Verbbedeutung den Zugang zur Konstruktion. Eine konstruktionsbasierte Abgrenzung von ein schönes Lächeln lächeln, einen lauten Seufzer seufzen (Output) zu dicke Tränen weinen (Begleitumstand) ist nicht nachvollziehbar. Viel wesentlicher ist

148 forum.worldofplayers.de/forum/threads/1325726-Setarrif-39/page5

149 In diesem Sinne kann durchaus von einem verbal lizenzierten KO - analog zu einen Bau bauen - gesprochen werden. Indiz hierfür wäre auch, dass entsprechende Verben seit dem Althochdeutschen verschiedene Argumentkonstruktionen zum Ausdruck des Inhalts nutzen bzw. sich diese an jenen Verben herausbilden. Admoni (1990: 37) zeigt dies für das Verb gilouben, welches mit Genitiv-, Akkusativ- und präpositionalem Objekt gebraucht wird. Durch die KO-Konstruktion wäre die Ambiguität zwischen dem Glauben an Bestehendes (glauben an) und dem Hervorbringen des Glaubens (glauben + Akkusativ) aufgelöst. 
die Abgrenzung der KO von pseudo-inkorporierten Nomen wie Rotz und Wasser heulen. Letztere sind typischerweise nicht determiniert. Sie werden auch nicht modifiziert und sind im Gegensatz zu KO nicht pronominalisierbar.

Aus diesem Grund wird auch Winklers (ebd.: 25) Analyse von Tango/Walzer tanzen als Instanzen einer KO-Konstruktion abgelehnt. Winkler (ebd.) beschreibt jene KO als durch das Verb ausgeführte Muster und zählt sie daher zum Randbereich von KO. Zu den KO - und dann nicht zum Randbereich - zählen nur determinierte Nomen. Die entsprechende Musterlesart wurde unter Verweis auf Dowty (1979: $69 \mathrm{f} .$, 186f.) unter dem Stichwort „creation of performance objects“ angesprochen. Wesentlich ist, dass nicht nur entsprechende perform-Verben, sondern die KO-NP selbst festlegen, ob es sich eher um die Ausführung eines Musters (40a) oder aber das erstmalige Hervorbringen (40b) handelt. ${ }^{150}$

(40) a. «Wir tanzen den Tanz des Volkes», und weiter meinte er: «Alle Kongolesen tanzen ihn.» ${ }^{151}$

b. Tod und Liebe tanzen einen wilden Tanz miteinander $[\ldots]^{152}$

Die beiden diskutierten konstruktionsgrammatischen Analysen sind zu weit und zu eng gefasst. Höche zählt unabhängig vom Ereignistyp (affizierte vs. effizierte Objekte) alle Äußerungen mit deverbaler Objekt-NP zu den KO. Winkler hingegen analysiert nur etwas im weitesten Sinne durch das Verbalgeschehen Hervorgebrachtes als KO, allerdings ohne jene Relation konstruktionell zu erfassen. Auf der anderen Seite geht Winkler weit über die Relation des Hervorbringens (sei es als Muster, Begleitumstand oder Inhalt) hinaus und zählt auch klare Adverbiale wie mit der Laubsäge sägen durch die Stammverwandtschaft zum Verb zu den KO. Zu eng scheint Winklers Analyse, da Sprecher und Hörer zwischen abgespeicherter Verbbedeutung und Konstruktionsbedeutung nicht mehr ,verhandeln“ müssen. Eins-zu-eins sind beide aufeinander abgestimmt. Raum für konstruktionsinterne kompositionelle Prozesse gibt es nicht. Eingedenk der grundsätzlichen Ambiguität zwischen Objekt- und Vorgangslesart deverbaler Nomen ist die diesbezügliche Festlegung durch die Argumentkonstruktion genauso zu eng wie die Festlegung auf die Lesart einer Musterrealisierung.

150 Auf entsprechende Ambiguität zwischen Musterrealisierung und erstmaligem Hervorbringen macht auch Dowty (1979: 70) aufmerksam und bemerkt, dass jene Unterscheidung grammatisch und semantisch (in Bezug auf die Telizität der Gesamtäußerung) keinen Einfluss hat.

151 St. Galler Tagblatt, 11.11.1998.

152 Nürnberger Nachrichten, 10.05.1994, S. 19. 


\subsection{Ereignissemantische Analyse im HPSG-Format}

Manfred Sailers (2010) Vorschlag für das Englische basiert auf den Daten von Höches Korpusanalyse. Er (ebd.: 204) schlägt im Rahmen der HPSG eine Lizenzierung von KO durch vier miteinander verwandte Lexikonregeln vor. Die Lexikonregeln verändern die Merkmalslisten entsprechender Verben und führen dazu, dass intransitive Verben transitiv gebraucht werden. Input der vier Regeln können demzufolge nur intransitive, unergative Verben sein. Ihr Output verfügt über ein zusätzliches syntaktisches Argument, das KO. In allen Fällen muss das neu eingeführte Argument lexikalisch und semantisch denselben grundlegenden Beitrag wie das Verb liefern, wodurch die ,Kognatheit' des neu eingeführten Arguments sichergestellt werden soll. ${ }^{153}$ Die vier von Sailer vorgeschlagenen Regeln lizenzieren Konstruktionen mit objekt- und vorgangsdenotierendem KO, welche jeweils eine konkrete oder generische Lesart haben können.

Anders als in den diskutierten konstruktionsgrammatischen Analysen bezieht Sailer typische Modifikations- und Determinationsmuster der KO mit ein. Aus Höches Daten extrahiert er (ebd.: 195f.) häufige formale Cluster der KO-NP und ordnet ihnen typische Lesarten zu. Diese modelliert er ereignissemantisch.

Die nach Höches Daten größte Gruppe von KO stellen indefinite, mit einem Adjektiv modifizierte KO wie to live a happy life dar. Nach Sailer (2010: 197) handelt es sich um „Particular Event“ denotierende KO. Das Verb und das KO würden auf das gleiche Ereignis referieren. ${ }^{154}$ Durch die konkrete Ereignislesart hält Sailer die Umformung in ein Adverb (to live happily) für äquivalent und das KO für nicht pronominalisierbar. Die Gesamtäußerung ist atelisch. Passivbelege finden sich für diesen Typ in Höches Daten nicht und würden nur selten in der Literatur auf-

153 Sailer (2010: 204) kennzeichnet dies als inhaltliches Merkmal MAIN durch einen Index, lockert aber im Fazit (S. 210) angesichts möglicher Variation die Regel, indem er auch hyponyme Nomen zulässt. Dies wurde in Bezug auf ein Grinsen lächeln ebenfalls als zu restriktiv dargestellt, da Grinsen kein Hyponym von Lächeln ist.

154 Anstelle von Referenz-Identität erscheint es mir plausibler, dass die Ereigniszeit der Nominalreferenz der des Verbs gleich sein kann aber auch kleiner [Verb (e) $\geq$ Nomen (e')]. Denn das KO-Ereignis kann durch die Modifikation als Kulminationsphase verstanden werden, wodurch die Zeit des Verbalereignisses sich nicht deckt mit der Zeit des Nominalereignisses. Wird ein schönes Lächeln gelächelt, so muss es noch nicht zu Beginn des verbal ausgedrückten Lächelns schön sein. Möglich ist aber, dass gerade in diesem Fall die Objektlesart anstelle der Ereignislesart des KO präferiert wird. Ebenso sind konträre Modifikationen des Verbs und des KO möglich. Ein glückliches Leben kann unglücklich gelebt werden. Allerdings kann in diesem Falle die generische Lesart den Konflikt lösen. 
geführt. ${ }^{155}$ Unter 3.1 wurde die denotative Perspektive, unter der Adverbial und KO bedeutungsgleich sind, abgelehnt. Begründet wurde dies mit Verweis auf die Argumenthaftigkeit, welche sich bei der Gegenüberstellung von KO mit appositiver NP und Adverbial deutlich zeigt. Daher ist Sailers Vorschlag unbefriedigend. Denn Sailer (ebd.: 197) wertet diese KO zwar syntaktisch als Argumente, lässt sie semantisch aber unter den Tisch fallen, indem er Alex lived a happy life wie folgt (41) semantisch repräsentiert.

(41) $\exists e($ live(e) $\wedge$ happy(e) $\wedge \operatorname{Arg} 1(\mathrm{e}$, Alex $))$

Dies ist umso erstaunlicher, da Sailer (2010: 206) ein semantisches Prinzip formuliert (Principle of Semantic Discernibility), demzufolge der semantische Beitrag des KO nicht vollständig im Verb enthalten sein dürfe. ${ }^{156}$ Offensichtlich wird so die typische Modifikation von KO erklärt. Unklar ist aber, warum ein semantisches Prinzip auf eine syntaktische Einheit angewandt werden soll, die in der semantischen Repräsentation (41) nicht erscheint.

Eine andere Regel lizenziert nach Sailer (2010: 197f.) eine gleichförmige KO-NP, welche aber auf effizierte Objekte referiert (concrete effected object reading). Diese KO hält Sailer für referentiell, pronominalisierbar und quantifizierbar. Die Gesamtäußerung ist telisch. Als Beispiel führt Sailer (ebd.: 198) Bailey sighed a deep sight an. Die semantische Repräsentation wird in (42) wiedergegeben.

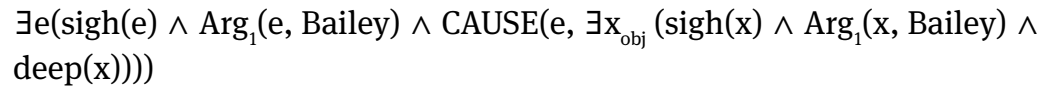

Das syntaktische Argument ist auch ein semantisches. Die Konstruktion steuert die Komponente des Hervorbringens (CAUSE) und die Argumentstelle (x) für das KO bei. Das Verb bringt sein erstes Argument in die Konstruktion mit ein und bezeichnet die Art und Weise des Hervorbringens. Im Fall von (42) wird der Seufzer eben seufzend hervorgebracht. Analog dazu sollte bei (41) das glückliche Leben ebenso lebend hervorgebracht werden. In beiden Fällen ist das KO im Deutschen pronominal wiederaufnehmbar (43).

155 Sailer (2010: 195) verweist auf Kuno \& Takami (2004: 133). Unter (29a) wurde ein Beleg für das Deutsche aufgeführt.

156 Sailer (2010: 126) schreibt allgemeiner, dass der semantische Beitrag einer Tochter nicht vollständig in einer anderen Tochter enthalten sein dürfe. 
(43) a. Er hat doch auch [...] ein Recht darauf, eine Biographie zu haben, ein Recht darauf, ein Leben gelebt zu haben, auch wenn fast gar nichts Spektakuläres in ihm passiert ist. ${ }^{157}$

b. Meine Mutter seufzte den Seufzer, den ich unter hunderttausenden identifiziert hätte. Ich kannte ihn aber auch bereits seit beinahe vierzig Jahren. ${ }^{158}$

Anders als Höche und Winkler nimmt Sailer zwei weitere Konstruktionen an, in denen die jeweilige KO-Lesart als Ereignis oder Objekt generisch verstanden wird. Sailer (ebd.: 200) schreibt bei I lived the life of a slave von einem „generic event“KO. Unter 2.3 wurde auf den Auslöser jener Lesart eingegangen. Da das Subjekt und im Englischen die PP, im Deutschen die entsprechende Genitiv-NP (das Leben eines Sklaven) nicht koreferent sind, wird die definite NP the live of a slave generisch verstanden. Nach Sailer (ebd.: 201) fungiert das verbal ausgedrückte Ereignis als Instanz des Typs, welcher durch das KO ausgedrückt wird. Unklar ist, warum es durch die Regel, welche das KO lizenziert, vorgegeben sein sollte. Denn offensichtlich ergibt sich jene Lesart kompositionell durch die gesamte ObjektNP. Zu bedenken ist außerdem, dass das KO nicht als Instanz eines Typs verstanden werden muss. Es kann auch als singuläre hervorgebrachte Entität wie in (44) verstanden werden.

(44) Sagt es und lächelt das Lächeln der Machtwollerin. Nein, diese Angela Merkel wird so schnell nicht von Guttenberg abgelöst. ${ }^{159}$

In Äußerungen wie he smiled the smile of reassurance oder he smiled his irresistible smile bezeichnet Sailer (ebd.: 201) das KO als „abstract (kind) object“. Die konkrete hervorgebrachte Entität ist selbst Instanz des Typs, welchen das KO ausdrückt. Auch hier erscheint es plausibler, die Generizität kompositionell herzuleiten als sie konstruktionell durch die das KO lizenzierende Regel vorzugeben. Die generische Lesart wurde unter 2.3 auf die Definitheit der NP zurückgeführt. Im Falle der Possessivdeterminatoren wird das KO als für das Subjekt typische Entität (sein unwiderstehliches Lächeln) oder eben als dessen Art eines etablierten Typs (seinen Heldentod sterben) verstanden. Im Deutschen gibt es keinen Grund dafür, bei das Lächeln der Zuversicht lächeln ausschließlich die Objektlesart anzunehmen. Sailers denotativer Sicht zufolge, die abgelehnt wurde, wäre eine

157 Peter Bichsel: Im Gegenteil. Frankfurt a. M., 1999, S. 66.

158 Eva Rossmann: Kaltes Fleisch: Ein Mira-Valensky-Krimi. Folio Verlag, 2012.

159 FOCUS, 08.11.2010, S. 13. 
Umformung des KO in den adverbialen Ausdruck zuversichtlich lächeln ebenso möglich.

Sailers Analyse gibt viel Aufschluss über die Möglichkeiten, Äußerungen mit KO zu verstehen und formalisiert jenes Verständnis ereignissemantisch. Ein wesentlicher Kritikpunkt ist, dass die häufig innerhalb einer KO-Äußerung bestehende Ambiguität zwischen Ereignis- und Objektlesart durch eine Regel aufgehoben werden soll, die das jeweilige KO lizenziert. Eine solche Regel ist, gemessen an den Daten, zu restriktiv. Ein weiterer Kritikpunkt ist: Selbst bei klarer Ereignislesart des KO sollte es nicht nur syntaktisch, sondern auch semantisch als Argument analysiert werden.

\section{Konstruktion und Komposition}

Nach Darstellung und Eingrenzung des Phänomens im ersten Abschnitt sowie der Diskussion bisheriger Analysen schlage ich unter 4.1 eine unterspezifizierte konstruktionsgrammatische Analyse vor. Unter 4.2 werden die besprochenen verschiedenen Eigenschaften von KO-Äußerungen konstruktionsintern kompositionell erklärt.

\subsection{Konstruktion als Lizenzierung kognater Objekte}

Anstelle einer Lexikonregel, welche einem Verb Merkmale hinzufügt und es so für eine KO-Konstruktion präpariert, schlage ich direkt eine Argument-Konstruktion vor. Dies wird der Tatsache gerecht, dass Äußerungen mit KO in Bezug auf ihre Argumente eine vorhersagbare Form und Bedeutung haben, und zwar unabhängig davon, ob es sich bei entsprechenden Verben um intransitivite activityVerben, sogenannte unakkusativische Verben oder affizierende transitive Verben handelt. Für eine konstruktionelle Analyse spricht ebenso das nötige Informationsplus (Modifikation i. w. S.), welches über die elementare KO-Konstruktion hinausgeht. Ein weiteres Argument für eine holistische Analyse ist, dass bis auf wenige Verben, welche frequent mit einem KO gebraucht werden, viele Verben nur sehr selten neben ihrem Normalgebrauch auch mit KO auftreten. Beide Tatsachen lassen sich konstruktionsgrammatisch gut erfassen. Je häufiger ein Verb (Token-Frequenz) in einer bestimmten syntaktischen Konfiguration gebraucht wird, umso eher schleift sich jener syntaktische Gebrauch im Sinne eines zusätzlichen Lexikoneintrags ein. Im Gegenzug führt die hohe Type-Frequenz auf der Verbstelle zur Abstraktion, d.h. Schematisierung der Konstruktion selbst und 
begründet den produktiven Gebrauch von KO. ${ }^{160}$ Unter (45) werden die Form- und Bedeutungsseite der KO-Konstruktion dargestellt.

\begin{tabular}{|ccc|}
\hline $\mathrm{NP}_{\text {Nom }}$ & $\mathrm{V}^{1}$ & $\mathrm{~N}^{1} \mathrm{P}^{\mathrm{MOD}}$ \\
\hline $\mid$ & & \\
\hline $1 . \mathrm{Arg}$ & & $2 . \mathrm{Arg}$ \\
\hline $\mathrm{Ag}$ & $\mathrm{EFF}$ & $\mathrm{Pat}_{\mathrm{E} / \mathrm{O}}$ \\
\hline $\mathrm{Ag}$ & & \\
\hline
\end{tabular}

Die Konstruktion verfügt über zwei Argumente, welche formal als NP im Nominativ und als NP im Akkusativ ausgezeichnet sind. Zur Bedeutungsseite zählen primär die Kodierung der Reihenfolge der Argumente (1., 2. Arg.) im Sinne Welkes (2001: 273f.) logisch-pragmatischer Rollen und dem daraus entwickelten perspektivischen Rollenkonzept Rostilas (2007: 66-68, 282-284). Die Konstruktion gibt durch die Reihenfolge ihrer Argumente eine Perspektive vor, unter der ein Ereignis sprachlich konstruiert wird. Jene perspektivischen Rollen dienen auch als Vermittlungsinstanz zu den semantischen Rollen. Denn es handelt sich in Nominativ-Akkusativ-Sprachen um eine typische Zuordnung zwischen erstem Argument und Proto-Agens (Ag) sowie zweitem Argument und Proto-Patiens (Pat), in diesem Fall effiziertem Patiens. Die Tatsache, dass die NP im Akkusativ als zweites und damit letztes Argument ausgezeichnet ist, erfasst eine gewisse Zielrichtung der Situationsdarstellung. Dies ist die Erklärung dessen, was Höche (2009: 193) als „,bounding“-Effekt von KO erwähnt und Horrocks \& Stavrou (2010: 302) als „some natural limit on an otherwise open-ended activity“ beschreiben. Die Ereignisdarstellung zielt auf das Hervorbringen des zweiten Arguments ab. Die konkrete für KO typische Relation des Effizierens wird durch EFF erfasst. Ob Äußerungen mit KO telisch oder atelisch referieren, wird nicht durch die Konstruktion festgelegt. Ebenso bleibt offen, ob das effizierte Patiens eventiv (E) als nomen actionis oder als Objekt (O), also als nomen acti verstanden wird. Zuordnungstendenzen wurden bezüglich verschiedener Nominalisierungsmuster besprochen.

Was sprachlich kompakt in der effizierenden Nominativ-Akkusativ-Konstruktion als Agens verpackt ist, ist nicht direkt Agens der Relation des Hervorbringens. Hierauf deutet die Analyse von Kausativstrukturen von Dowty (1979: 91) hin. Für den Satz „John killed Bill“ schlägt er folgende semantische Struktur vor (46).

160 Cf. Bybee (1995: 434). 
(46) [[John does something] CAUSE [BECOME $\neg[$ Bill is alive]]]

Das Tun des ersten Arguments löst die Verursachungsrelation aus. In diesem Sinne ist das Ereignis, welches durch das Subjekt und das Verb ausgedrückt wird, das erste Argument der Verursachungsrelation. Welke (2005: 185) baut diese Analyse aus. Seiner Notation folgend, stelle ich die semantische Struktur kognater Objekte bzgl. der Prädikation in (47a) und im ereignissemantischen Format nach Sailer (2010: 198) in (47b) dar.

(47) a. DO $\{\mathrm{x},[$ CAUSE $((\mathrm{DO}(\mathrm{x}, \mathrm{PROC}(\mathrm{x}))),($ BECOME exist $(\mathrm{MOD}(\mathrm{y}))))]\}$

b. $\left.\left.\exists \mathrm{e}\left(\mathrm{DO}(\mathrm{PROC})(\mathrm{e}) \wedge \operatorname{Arg}_{1}(\mathrm{e}, \mathrm{x}) \wedge \operatorname{CAUSE}(\mathrm{e}, \exists \mathrm{y}(\mathrm{y})) \wedge \operatorname{Arg}_{1}(\mathrm{y}, \mathrm{x}) \wedge \operatorname{MOD}(\mathrm{y})\right)\right)\right)$

In (47) steht der erste Funktor DO für ein willentliches Tun, welches einen Vorgang (PROC) auslöst, um eine Entität (y) hervorzubringen. ${ }^{161}$ Dies trifft zu, wenn jemand absichtlich ein freundliches Lächeln lächelt. Fehlt das willentliche Tun, z. B. wenn jemand ein lautes Schnarchen schnarcht, dann fehlt der erste DOFunktor. Im Falle der unakkusativischen Verben fehlt auch das zweite DO in (47a), denn das erste Argument (x) ist dem Vorgang unterworfen (PROC(x)), welcher zum Hervorbringen der Entität (y) führt, z. B. wenn jemand einen tiefen Fall fällt. Die semantische Struktur und ihr Ausdruck sind durch effizierende Verben und ihre Argumentstruktur motiviert, bzw. von dieser abgeleitet. Die Besonderheit vieler durch die KO-Konstruktion lizenzierten Äußerungen ist, dass keine sukzessive Beziehung zwischen dem Tun oder dem Vorgang des ersten Arguments (x) und dem Entstehen des zweitem Arguments (y) bestehen muss. Mit dem LächelnEreignis ist das Lächeln-Resultat da, sowohl die Geste als auch das als Redegegenstand verdinglichte Ereignis. Mit einem Bauen-Ereignis ist ein Bau nicht sofort da. Hierauf komme ich noch einmal zurück. In der semantischen Analyse ließe sich das durch Ersetzen oder Kombinieren von BECOME (als Übergang in den neuen exist-Zustand) durch INGR (typisch für achievements, also als Beginn des neuen exist-Zustands) modellieren. Diesbezüglich spielt die Modifikation des KO eine wichtige Rolle. Schneidet ein Chirurg oder Friseur einen Schnitt, so ist zwar mit dem Ereignis des Schneidens ein Schnitt da, aber noch kein modischer oder langer Schnitt.

Anders als die Argumentstruktur von verba efficiendi verfügt die KO-Konstruktion über ein zusätzliches Merkmal, welches durch den Index 1 am Verbslot und am Nomen der NP im Akkusativ vermerkt ist. Dieses Merkmal betrifft nicht nur die Stammverwandtschaft zwischen Verb und Nomen oder deren seman-

161 Mit MOD(y) wird dargestellt, dass y typischerweise Argument eines Modifikators ist. 
tische Verwandtschaft (Ko-Hyponymie). Der Index ist auch als Link zu bestehenden Nominalisierungsmustern (Konstruktionen) $\mathrm{zu}$ verstehen und erfasst als Präferenzregel (48), dass bestehende heute nicht mehr produktive Stammkonversionen und Derivata präferiert vor den produktiven Infinitivkonversionen als nominaler Kern der NP genutzt werden (48a). Dies ist verständlich, da die Stammkonversionen und Derivata als Kerne von NPs typischerweise über eine gequantelte Referenzweise verfügen und somit das prototypische Nominalkonzept ausdrücken. Stammableitungen auf -er (48b) wurden unter 2.2 als Ausdrücke einer einzigen Episode des Verbalvorgangs beschrieben. Ihr Gebrauch ist beschränkt auf Verben der Lautäußerung und scheint stark durch das formal identische Muster zur Bildung von nomina agentis beschränkt zu sein. Teilweise ist alternativ der iterative Nominalausdruck mit $\mathrm{Ge}-(-e)$ möglich (48c). Die dargestellten Möglichkeiten interner Variation, was jenen nominalen Kern betrifft, sind ein Faktor für die Produktivität von KO.

(48) a. [Verbstammkonversion] $]_{\mathrm{N}}$ (einen Kampf vs. \#ein Kämpfen kämpfen) oder [implizite/explizite Derivation] $]_{\mathrm{N}}$ (einen Wurf vs. \#ein Werfen werfen) > [Infintivkonversion $]_{\mathrm{N}}$ (ein leises Seufzen seufzen)

b. [Verbstamm-er] $]_{\mathrm{N}}$, ,Single Unit' (einen kleinen Seufzer seufzen)

c. $[\text { Ge-Verbstamm-(-e) }]_{\mathrm{N}}$ - ,Iterativität‘ (ein lautes Gegacker gackern)

Das an der Akkusativ-NP vermerkte Merkmal MOD weist auf das notwendige Informationsplus hin. Es ist ebenfalls als Link zu den nominalen Modifikatorkonstruktionen zu verstehen, welche häufig mit KO gebraucht werden (49).

(49) a. $[\mathrm{AP}+\mathrm{N}]_{\mathrm{N}}$

b. $\left[\mathrm{NP}_{\mathrm{Gen}}+\mathrm{N}\right]_{\mathrm{N}}$

c. $\left[\mathrm{N}+\mathrm{NP}_{\mathrm{Gen}}\right]_{\mathrm{N}}$

d. $[\mathrm{N}+\mathrm{PP}]_{\mathrm{N}}$

e. $[\mathrm{N}+\text { Relativsatz }]_{\mathrm{N}}$

Auch (49b,c) wird Welke (2016: 78-86) folgend primär als Attribut-Konstruktion klassifiziert. Die Genitiv-NP drückt in Nominalkonstruktionen den Possessor (im weiteren Sinn) aus. Das Lächeln der Sieger ist demnach primär ein Lächeln, das zu Siegern gehört. Die Möglichkeit der Ereignislesart des deverbalen Nomens macht nun auch die agentive Lesart als genitivus subjectivus möglich und gleicht das Attribut mit dem ersten Argument des zugrunde liegenden Verbs ab. Unter dem Merkmal MOD wird auch erfasst, dass ein KO häufig mehrfach modifiziert ist. Konstruktionsgrammatisch ist dies als Einbettung verschiedener Konstruktionen ineinander beschreibbar. So basiert das strahlende Lächeln der Sieger auf 
(49a) und (49c). Im weiteren Sinne zählt auch die Kompositabildung (das Siegerlächeln) zu den Möglichkeiten nominaler Modifikation, auch wenn es sich eher um Begriffsbildungen (Typen) als um Bezeichnungen für Untermengen von Entitäten handelt.

Die Ausweisung des KO als NP beinhaltet die Notwendigkeit der Determination. Besonders die Possessivartikel leisten zusätzlich, was typischerweise die Funktion von Modifikatoren ist. Sie determinieren das nominale Prädikat bezüglich einer Eigenschaft. Denn Possessivartikel drücken die Eigenschaft der Zugehörigkeit aus. Möglich wäre es auch, häufige Muster der gesamten KO-NP holistisch zu erfassen, was Sailer (2010) vorgeschlagen hat. Hierzu wäre eine umfassende Korpusrecherche für das Deutsche nötig. Für das Verb lächeln wurden unter 2.3 die verschiedenen Modifikations- und Determinationsmuster auch quantitativ betrachtet.

Was die möglichen Verben angeht, welche den Verbslot der Konstruktion besetzen können, wurde in 2.1 gezeigt, dass viele Annahmen in der Fachliteratur $\mathrm{zu}$ restriktiv sind. Als Grundprinzip gilt das in 3.3 vorgestellte Korrespondenzprinzip von Goldberg. Das Verb muss als Instanz der in (45) dargestellten Relation des Hervorbringens konzeptualisierbar sein. In 2.1 wurde gezeigt, dass dies besonders bei intransitiven activity-Verben der Fall ist. Als Untergruppen wurden Verben erwähnt, deren Bedeutung eine Output-Komponente (gestischer, akustischer, dinglicher Natur) beinhaltet. Im Randbereich können auch Zustandsverben analog $\mathrm{zu}$ diesen activity-Verben mit KO gebraucht werden. Bei (Fort-) Bewegungsverben kann der Weg oder dessen Form als Ergebnis der Bewegung konzeptualisiert werden. Diese Verben bringen ihr erstes verbales Argument als Agens bzw. Mover (Proto-Agens) in die Konstruktion ein. Mentale Verben wie denken, träumen, fühlen bilden ihr erstes Argument, einen Experiencer, auf die Agensrolle der Konstruktion ab. Die Grenzen zwischen willentlich kontrolliertem Träumen und Denken und den nicht willentlich steuerbaren Pendants sind fließend und werden sprachlich konstruiert. Das im Verb angelegte Merkmal „Inhalt“ wird im Rahmen der KO-Konstruktion als Resultat umgedeutet. Bei äußerst schwacher Agentivität des Verbs (schlafen) bis hin zu sogenannten unakkusativischen Verben ist das Merkmal ,Durativität' bzw. ,konzeptualisierbare Durativität‘ für den Zugang zur KO-Konstruktion wesentlich. Der wesentliche Unterschied ist, dass nur die unakkusativischen Verben einen Endzustand präsupponieren.

Es ist möglich, die Verbgruppen, welche häufig mit KO gebraucht werden, als eine Art Fusionsroutine an der Konstruktion zu vermerken (50). Auffällig ist, dass die Verbgruppen (50a, c-e) eine gewisse zweigliedrige Semantik auszeichnet. Diese wird nicht als eine unter der Hand angenommene transitive Argumentstruktur analysiert, sondern als semantisches Merkmal, welches den Zugang zu der KO-Konstruktion erleichtert. Bei (50f) führt erst die Einbettung in die Kon- 
struktion zu jener zweigliedrigen Merkmalsstruktur, bzw. hebt schwach angelegte Merkmale der Verbbedeutung wie leben - Livestyle oder schlafen - Art oder Dauer hervor.

(50) a. Emission: Geste/Flüssigkeit/Laut/Kraft (ein schönes Lächeln lächeln)

b. Zustand analog zu (a) (ein helles Strahlen strahlen)

c. Bewegung: Weg/Form (einen hohen Sprung springen)

d. Fühlen/Denken: Gefühl/Gedanke (ein tiefes Gefühl fühlen)

e. Prozess: Resultat (einen friedlichen Tod sterben)

f. durative Aktivitäten (einen tiefen Schlaf schlafen)

Eine andere Quelle für die Produktivität von KO bilden Verben, die wie lächeln sehr häufig mit einem KO gebraucht werden. Aufgrund der hohen Assoziationsstärke ist anzunehmen, dass die KO-Konstruktion neben der klassischen Valenz Teil des Verbeintrags ist. Diese Verben bilden mit ihrer KO-Konstruktion einen Prototyp im Sinne eines Vorläufers, von dem aus Ableitungen möglich sind. ${ }^{162}$ Dies wurde anhand von ein Lächeln lächeln und entsprechenden Ableitungen im Verbal- (ein Lächeln schmunzeln/grienen/grinsen) und Nominalbereich (ein Lächeln/Grinsen/Schmunzeln lächeln) in 2.2 dargestellt.

Werden transitive affizierende Verben mit einem KO gebraucht (einen Kuss küssen), dann blockiert das durch die Konstruktion lizenzierte effizierte Objekt das verbale affizierte Objekt (jdn. küssen). Die Einbettung in die Konstruktion führt zu einer neuen Lesart, nämlich der des Hervorbringens.

Wie sieht es mit effizierenden Verben aus, die mit einer Objekt-NP gebraucht werden, deren Kern morphologisch vom Verb abgeleitet ist (einen Bau bauen)? Ihre Lizenzierung ist die verbale Argumentstruktur. Die stilistische Besonderheit führt zur Deckungsgleichheit mit Äußerungen, die auf der KO-Konstruktion beruhen. Der Gebrauch transitiver effizierender Verben mit einer morphologisch vom Verb abgeleiteten Objekt-NP motiviert die Form und die Funktion der KOKonstruktion.

Durch die vorgeschlagene Konstruktion bleiben viele Eigenschaften und Lesarten unterspezifiziert. Daher wird im folgenden Abschnitt gezeigt, wie sich diese durch kompositionelle Prozesse innerhalb der Konstruktion ergeben und dass diese somit nicht an die Konstruktion, welche das KO lizenziert, gebunden werden müssen bzw. können.

162 Cf. Bybee (2010: 100). 


\subsection{Komposition und coercion}

Die erste, bereits angesprochene Veränderung der Lesart findet statt, wenn intransitive oder transitive affizierende Verben als Instanzen der KO-Konstruktion gebraucht werden. In diesen Fällen überschreibt die Konstruktionsbedeutung einen Teil der Verbbedeutung. Michaelis (2003: 167 f.) nimmt an, dass Konstruktionen ihre Bedeutung lexikalischen Konstruktionsinstanzen aufzwingen, bzw. die Bedeutung letzterer überschreiben, daher auch „override-principle“ oder „coercion“. Entsprechende Prozesse sind aber als beidseitige Einpassungen und Lesartveränderungen zu verstehen.

Von gegenseitiger Anpassung kann gesprochen werden, wenn auch das Verb die Lesart oder Eigenschaften der Konstruktion verändert. Dies ist bei den unakkusativen Verben der Fall. Ihr erstes Argument setzt sich als dem Verbalvorgang unterworfene Größe gegenüber dem Agens der Konstruktion durch. Dies erklärt, dass trotz Gebrauch mit einem KO das Perfekt mit sein gebildet wird. Bei den Verben der (Fort-)Bewegung setzt sich bezüglich des Perfekts mal die Konstruktion (Auxiliar haben) und mal das Verb (Auxiliar sein) durch.

Im Folgenden werden Fälle besprochen, bei denen es zu konstruktionsinternen Überschreibungen von Eigenschaften der gesamten Konstruktion oder aber zur Veränderung der Referenzweise einzelner Teile der Konstruktion kommt.

Zuerst wird der Frage der Zeitkonstitution nachgegangen. Unter 3.2 wurde dargestellt, dass effizierende Relationen eigentlich klar telisch sein sollten. Das ist jedoch häufig nicht der Fall. Nach Krifka (1989: 158) ist eine Bedingung für eine telische Referenzweise die Übertragung der gequantelten Referenzweise des Objektes auf die gesamte VP. Unter 2.2 wurde der Begriff der Quantelung als wesentliches Merkmal von Individualnomen im Gegensatz zur Kumulativität von Massennomen eingeführt. Die Rolle der Objekt-NP kann deutlich gemacht werden, wenn wir die ungequantelte Objekt-NP (Bauten in 51a) mit der gequantelten NP in (51b) vergleichen.

(51) a. Wir bauen Bauten für unsere Zukunft. ${ }^{163}$

b. Sie bauen nicht irgendeinen Bau, sondern den Prestigebau für die Propaganda-veranstaltung des Jahrzehnts. ${ }^{164}$

In beiden Fällen handelt es sich um die Objektlesart des Nomens Bau. (51a) kann auf mehrere Ereignisse bezogen oder generisch verstanden werden. In (51b) geht

163 Burgenländische Volkszeitung, 11.03.2009, S. 27.

164 Neue Zürcher Zeitung, 17.06.2008, S. 17. 
es um eine konkrete Token-Lesart. In (51a) wird ein atelisches Ereignis beschrieben, in (51b) hingegen ein telisches. Die Objekt-NP in (51a) überträgt ihre kumulative Referenzweise auf die gesamte VP. Daher fallen zwei Ereignisse ,Bauten bauen' auch wieder unter ,Bauten bauen'. Bei (51b) ist das nicht der Fall. Die gequantelte Referenz von den Prestigbau, sofern er nicht generisch als Typ verstanden wird, überträgt sich auf die gesamte VP. Zwei Ereignisse, auf die ,den Prestigebau bauen' zutrifft, fallen nicht mehr unter ,den Prestigebau bauen', sondern unter ,zwei Prestigebauten bauen‘. Jene Begrenzung führt zur telischen Lesart von (51b).

Nun können aber sowohl nomina actionis, die primär auf Vorgänge oder Zustände referieren wie Schlaf in einen tiefen Schlaf schlafen als auch nomina acti, die wie Gebäck kollektiv auf Objekte referieren, ungequantelt sein. Unter 2.2 wurde dargestellt, dass sich das deverbale Nomen Schlaf als Abstraktum wie ein Massennomen verhält, also kumulativ referiert. Hierin liegt ein Grund dafür, dass einen tiefen Schlaf schlafen eher atelisch ist. Die Kumulativität des Nomens Schlaf überträgt sich auf die gesamte VP. Analog dazu überträgt sich die kumulative Referenzweise von Gebäck in leckeres Gebäck backen auf die gesamte VP. Allerdings kann jene aufgrund der Nominalsemantik vorhersagbare Zeitkonstitution der VP auch wieder überschrieben werden. Wenn Schlaf in Bezug auf die Dauer modifiziert wird (52a) und Gebäck zusammen mit einer Numerativkonstruktion gebraucht wird (52b), dann werden die NPs gequantelt und übertragen diese Referenzweise auf die VPs. Diese bezeichnen daher in (52) telische Ereignisse.

(52) a. Es gibt scheints auch Männer, die aus dem Dornröschenschlaf wachgeküsst werden wollen. Die müssen aber auch den 100Jahre langen Schlaf schlafen, bis die Prinzessin kommt [...]. ${ }^{165}$

b. In den 80 Eurospar-Filialen werden täglich bis zu 2000 Stück Gebäck gebacken $[. . .]^{166}$

Anders als Real Puigdollers (2008: 161) und Sailer (2010: 198) annehmen, ist nicht die Objektlesart die Bedingung für Telizität. Ohne die NP-interne Quantelung von Gebäck (Objektlesart) und die von Schlaf (Vorgangs- oder Zustandslesart) wären die Äußerungen atelisch bzw. unterspezifiziert. Es ist die NP-interne Quantelung innerhalb der Relation des Hervorbringens, welche für die Telizität verantwortlich ist. Zweifelsohne gibt es eine gewisse Korrelation zwischen Ereignislesart

$165 \mathrm{http}: / /$ www.lovetalk.de/thema-liebe-als-diskussionsgrundlage/174563-single-frauen-aufder-suche-wo-trifft-sie-75.html

166 Neue Kronen-Zeitung, 21.02.1998, S. 6. 
und atelischer Zeitkonstitution sowie Objektlesart und telischer Referenz. Der Grund hierfür ist jedoch die jeweilige, abänderbare Referenzweise des Nomens.

Betrachten wir abschließend noch zwei Fälle, in denen die Objekt-NP gequantelt ist, die gesamte VP aber dennoch atelisch referiert. Unter 2.2 wurde auf die grundlegende Ambiguität vieler deverbalen Nomen hingewiesen. Es wurde gezeigt, dass ein Nomen wie Lächeln innerhalb der KO-Konstruktion objekthaft (ein brüchiges/kleines Lächeln) und eventiv (ein vorsichtiges/schnelles Lächeln) verstanden werden kann. Als entsprechende Auslöser wurden die Modifikatoren angeführt. Im Falle der Objektlesart wurde gezeigt, dass diese den Gebrauch als Individualnomen (zwei Lächeln vs. ${ }^{\star} z w e i$ Seufzen) ermöglicht. Aber selbst bei Objektlesart kann nicht klar von einer telischen Referenzweise der gesamten NP gesprochen werden.

(53) a. ?Anna lächelte in fünf Sekunden ein brüchiges Lächeln. - vs. Anna lächelte fünf Sekunden lang ein brüchiges Lächeln.

b. Wenn Anna dabei ist, ein brüchiges Lächeln zu lächeln, dann wird sie ein brüchiges Lächeln gelächelt haben.

Der Grund für die mangelnde Telizität liegt (sicher neben der schwachen Quantelung) darin, dass mit dem Verbalgeschehen lächeln sofort ein Lächeln da ist. ${ }^{167}$ Krifka (1989: 161) zeigt, dass eine weitere Bedingung für telische Referenzweise die schrittweise, sukzessive Veränderung bzw. Erzeugung des Objektes ist. Dies betrifft die bereits angesprochene Inkrementalität (Dowty 1991: $567 \mathrm{f}$.). Zwar muss mit dem Beginn des verbalen Lächelns nicht sofort ein brüchiges Lächeln da sein. Aber entsprechende minimal-sukzessive oder quasi-simultane Vorgänge erlauben es nicht, jedem Zeitpunkt des Verbalgeschehens einen bestimmten, bei effizierten Objekten anwachsenden Teil des Hervorgebrachten zuzuordnen. Jene Simultanität ist natürlich besonders stark, wenn das Nomen in seiner Ereignislesart verstanden wird. Offensichtlich führt auch die Modifikation nicht zu einem sukzessiv messbaren, anwachsenden Verhältnis zwischen Verbalgeschehen und Nominalvorgang. Daher lässt sich zumindest mittels der gängigen Tests keine Telizität nachweisen.

Betrachten wir nun den letzten Fall, in dem trotz Quantelung und Objektoder Ereignislesart, die VP atelisch ist (54).

167 Hierauf weisen auch Horrocks \& Stravou (2010: 302) hin. 
(54) a. Von wann bis wann wurde dieser Bautyp gebaut? ${ }^{168}$

b. Wir haben immer den guten Kampf gekämpft [... $]^{169}$

In (54a) liegt explizite Typenlesart vor, in (54b) ergibt sich diese durch die definite NP, welche ein kulturell etabliertes Konzept bezeichnet und das Adverbial immer. So wie ein Bautyp (im Gegensatz zu einem konkreten Bau) immer wieder und jahrelang gebaut werden kann, so kann der gute Kampf immer wieder gekämpft werden. Mit Krifka (1989: 198, 213) wurde bereits darauf hingewiesen, dass besonders die verba efficiendi zwei Lesarten definiter Objekt-NP erlauben, die als Konkreta und die als Typen. Wenn es sich um die Typen-Lesart handelt, dann überträgt sich die Quantelung der NP nicht auf die VP. Denn zwischen Verb und Objekt, so Krifka, besteht keine Ereigniseindeutigkeit. Ein bestimmter Typ kann durch verschiedene Verbalhandlungen realisiert werden. Das konkret Hervorgebrachte realisiert dabei in ungequantelter Art und Weise immer wieder den gleichen abstrakten Typ. Bestimmte Zeitpunkte des Verbalgeschehens lassen sich somit nicht bestimmten Abschnitten des hervorzubringenden Objekts zuordnen.

Die jeweilige Lesart des KO als Ereignis oder Objekt sowie das Verständnis als konkrete oder generische Entität lassen sich m. E. besser konstruktionsintern kompositionell herleiten, als sie vorwegzunehmen. Die Möglichkeiten, primäre Lesarten und vorhersagbare Eigenschaften durch An- und Einpassungsvorgänge zu verändern, werden nicht durch eine spezifische Argumentkonstruktion oder eine diesbezügliche Regel blockiert. Der Gewinn dieser Analyse ist erstens, dass die Lizenzierung von Äußerungen mit KO nicht exakter ist als ihr Output. Anders gesagt, gibt es gegen die Annahme der Konstruktion (45) keine negative Evidenz, da sie verschiedene Lesarten offenlässt. Zweitens sind die beschriebenen kompositionellen Prozesse einerseits über die KO-Konstruktion hinaus gültig. Es handelt sich also um allgemeine Prinzipien des schrittweisen Aufbaus von komplexen Bedeutungen aus weniger komplexen. Andererseits zeigt gerade die kompositionelle Herleitung der Zeitkonstitution, dass es spezifische Prinzipien für effizierte Objekte gibt. Hier unterscheiden sich die KO nicht von verbal lizenzierten effizierten Objekten. Dies ist ein klares Indiz für die Analyse von KO als effizierte Entitäten, welche syntaktischen und semantischen Argumentstatus haben.

$168 \mathrm{http}: / /$ www.schrankenposten.de/Posten/pofragen.html

169 Frankfurter Rundschau, 29.01.2009. Der Typ ist durch die Bibel, 1. Timotheus 6:12, etabliert: „Aber du, Gottesmensch, [...] kämpfe den guten Kampf des Glaubens“. 


\section{Fazit}

Der in dieser Arbeit gemachte Vorschlag einer unterspezifizierten KO-Konstruktion mit anschließender konstruktionsinterner Analyse kompositioneller Prozesse beruht auf zwei wesentlichen Grundlagen. Erstens muss der sprachlich fundamentale Unterschied zwischen Nominalreferenz und Verbalkonzept herausgearbeitet werden. Nur so können KO auch bei Ereignislesart des nominalen Kerns als syntaktisches und semantisches Argument erfasst werden. Zweitens ist signifikativ-semantisch vorzugehen. Das heißt, im Zentrum der Betrachtung steht die jeweilige sprachliche Konstruktion eines Ereignisses und nicht das (angenommene) Ereignis an sich oder eine dieses repräsentierende zugrunde liegende sprachliche Struktur. Ansonsten werden wir nur einer scheinbaren Dopplung zwischen Verb und KO gewahr. Gerade dessen Argumenthaftigkeit wurde im Gegensatz zu einer appositiven NP und zu scheinbar äquivalenten Adverbialen herausgearbeitet.

Bezüglich der Modellierung bei Ereignislesart des KO wurde offengelassen, ob das verbale und das nominale Ereignis-Argument identisch sind. Zu prüfen ist meine Annahme, dass das nominale Ereignisargument kleiner als oder maximal genauso groß wie das verbale ist, wenn der Beitrag der Modifikation als eine Art Kulmination gesehen wird.

Die verschiedenen Lesarten bezüglich der Ereignis- oder Objektlesart des KO, bezüglich eines konkreten und generischen Verständnisses sowie die sich daraus ergebende Zeitkonstitution wurden kompositionell durch konstruktionsinterne An- und Abgleichsprozesse erklärt. Dies widerlegt z. B. die Kritik von Leiss (2009: 27), dass es sich bei Konstruktionen um nicht analysierbare, strukturlose Einheiten handele. Ganz im Gegenteil sind sie der formale und semantische Rahmen innerhalb dessen die Einheiten kompositionell ,wirken'. Es wurde gezeigt, dass die KO-Konstruktion durch ihr zweites Argument eine Art Endpunkt, nämlich das effizierte Objekt vorgibt. Dies ist jedoch nicht mit Telizität gleichzusetzen. Diese ergibt sich konstruktionsintern $u$. a. aus der Quantelung der Objekt-NP.

Das Phänomen der KO mag, gemessen an der Frequenz anderer AkkusativNPs, peripher sein. Form und Bedeutung der Konstruktion liegen jedoch im Kernbereich von sogenannten Nominativ-Akkusativ-Sprachen. Welke (2009: 526) bezeichnet daher Nominativ-Akkusativ-Konstruktionen als „typologisches Etikett“. Daher wurde an vielen Stellen auf die Bezüge zu anderen gleichförmigen oder ähnlichen Konstruktionen hingewiesen. Mit allen teilt sich die KO-Konstruktion die perspektivische Auszeichnung des ersten Arguments (Nominativ) gegenüber dem zweiten (Akkusativ). Von der gleichförmigen affizierenden Konstruktion wurde die KO-Konstruktion klar unterschieden - allerdings mit dem Hinweis, dass manche Verben mit beiden Konstruktionen zum Ausdruck unter- 
schiedlicher Ereignisse gebraucht werden können. Unter synchroner Perspektive wurde der Bezug zu verbal lizenzierten effizierten Argumenten herausgestellt. Ebenso wurde auf Bezüge zum sogenannten adverbialen Akkusativ des Wegs (einen Flug/100 Meter fliegen) und der Zeit (ein schönes Leben/80 Jahre leben) hingewiesen. In diesem Sinne erscheint heute der Akkusativ des Inhalts als eine Art Bindeglied zwischen dem freien und dem verbal gebundenen Akkusativ.

Die Beziehung zwischen Verb und KO-Konstruktion wurde differenziert betrachtet. Verba efficiendi lizenzieren in jedem Falle ihr effiziertes Argument lexikalisch. Allein die Wahl eines mit dem Verb stammverwandten Nomens als Objekt führt zur Identität mit der KO-Konstruktion. Interessant wäre es, die quasi spiegelbildliche Parallelität zwischen intransitivem Gebrauch effizierender transitiver Verben und dem Gebrauch eigentlich intransitiver Verben mit KO kontrastiv in Hinsicht auf entsprechende Funktionen und Auslöser zu untersuchen.

Im Falle der intransitiven Verben lizenziert grundsätzlich die Konstruktion das KO. Der häufige Gebrauch eines Verbs mit KO führt jedoch wie alle anderen Kollokationen zur Einschleifung (entrenchment) der Konstruktion mit dem Verb. In diesem Fall handelt es sich um eine parallel zur klassischen Argumentstruktur vom Verb lizenzierte Konstruktion und das Konzept der Projektion steht dem der Konstruktion nicht gegenüber. Beide ergänzen einander.

Danksagung: Für Kommentare und Diskussion danke ich Eva Schlachter und Antonio Machicao y Priemer sowie den anonymen Gutachtern.

\section{Literatur}

Admoni, Wladimir G. (1990): Historische Syntax des Deutschen. Tübingen: Niemeyer.

Àgel, Vilmos (2017): Grammatische Textanalyse. Textglieder, Satzglieder, Wortgruppenglieder. Berlin, Boston: de Gruyter.

Bausewein, Karin (1990): Akkusativobjekt, Akkusativsätze und Objektsprädikate im Deutschen. Untersuchungen zu ihrer Syntax und Semantik. Tübingen: Niemeyer.

Behaghel, Otto (1923): Deutsche Syntax. 1. Band. (Germanische Bibliothek. Herausgegeben von Wilhelm Streitberg. 1. Reihe: Grammatiken. 10. Band.) Heidelberg: Winter’s Universitätsbuchhandlung.

Bierwisch, Manfred (1989): Event Nominalization: Proposals and Problems. In: Wolfgang Motsch (ed.): Wortstruktur und Satzstruktur (Linguistische Studien 194) Berlin: Akademie der Wissenschaften der DDR, S. 1-73.

Brinton, Laurel J. (1995): The Aktionsart of Deverbal Nouns in English. In: Bertinetto, Pier Marco/Bianchi, Valentina/Higginbotham, James \& Mario Squartini (eds.): Temporal reference, Aspect and Actionality. Vol. 1. Semantic and Syntactic Perspectives. Torino: Rosenberg \& Sellier, S. 27-42.

Burzio, Luigi (1986): Italian Syntax. A Government and Binding Approach. Dordrecht: Reidel. 
Bybee, Joan L. (1995): Regular Morphology and the Lexicon. In: Language and Cognitive Processes 10, S. 425-455.

Bybee, Joan L. (2010): Language, Usage and Cognition. Cambridge: Cambridge University Press.

Brugmann, Karl (1904): Kurze vergleichende Grammatik der indogermanischen Sprachen. Strassburg: Trübner.

Dal, Ingerid (2014): Kurze deutsche Syntax auf historischer Grundlage. 4. Auflage. Neu bearbeitet von Hans-Werner Eroms. In: Sammlung kurzer Grammatiken germanischer Dialekte. Herausgegeben von Thomas Klein \& Ingo Reiffenstein. B. Ergänzungsreihe. Berlin/Boston: de Gruyter.

de Swart, Peter (2007): Cross-linguistic Variation in Object Marking. (PhD dissertation, Department of Linguistics, Radboud University Nijmegen.) Utrecht: LOT Publications.

Dowty, David R. (1979): Word meaning and Montague grammar. The semantics of verbs and times in generative semantics and in Montague's PTQ. (Synthese language library, vol. 7.) Dordrecht, Boston, London: Reidel.

Dowty, David R. (1991): Thematic Proto-Roles and Argument Selection. In: Language 67 (3), S. 547-619.

Draeger, Kerstin (1996): Die semantinsche Leistung der Wortbildungsmorpheme der Substantive in der deutschen Gegenwartssprache. Aachen: Shaker.

Duden: Die Grammatik. (2016). 9., vollständig überarbeitete und aktualisierte Auflage. Herausgegeben von der Dudenredaktion unter Leitung von Angelika Wöllenstein. Mannheim, Zürich: Dudenverlag.

Engelberg, Stefan (2000): Verben, Ereignisse und das Lexikon. (Ling. Arbeiten 414). Tübingen: Niemeyer.

Ehrich, Veronica \& Irene Rapp (2000): Sortale Bedeutung und Argumentstruktur: -ung-Nominalisierung im Deutschen. In: Zeitschrift für Sprachwissenschaft 19.2, S. 245-303.

Felser, Claudia \& Anja Wanner (2001): The syntax of cognate and other unselected objects. In Dehé, Nicol \& Anja Wanner (eds.): Structural Aspects of Semantically Complex Verbs. Frankfurt, Bern \& New York: Peter Lang, S. 105-130.

Fleischer, Wolfgang \& Irmhild Barz (2012): Wortbildung der deutschen Gegenwartssprache. 4. völlig neu bearbeitete Auflage. Unter Mitarbeit von Marianne Schröder. Berlin, Boston: de Gruyter.

Garey, Howard B. (1957): Verbal Aspect in French. In: Language 33, S. 91-110.

Goldberg, Adele E. (1995): A Construction Grammar Approach to Argument Structure. Chicago, London: The University of Chicago Press.

Grimshaw, Jane (1990): Argument Structure. Cambridge Mass., London: MIT Press.

Grimshaw, Jane (2011): Deverbal Nominalization. In: Maienborn, Claudia/von Heusinger, Klaus \& Paul Portner (2011) (eds.): Semantics. An international handbook of natural language meaning. Volume 2. (HSK 33.2). Berlin, New York: Mouton de Gruyter, 1292-1313.

Handwerker, Brigitte (2010): Kollokationspartner der besonderen Art: Kognate Objekte im Deutschen. In: Estudios Filológicos Alemanes 21, S. 9-34.

Heidolph, Karl Erich/Flämig, Walter \& Wolfgang Motsch (1981): Grundzüge einer deutschen Grammatik. Berlin: Akademie-Verlag.

Helbig, Gerhard (1973): Die Funktionen der substantivischen Kasus in der deutschen Gegenwartssprache. Halle (Saale): VEB Niemeyer.

Helbig, Gerhard \& Joachim Buscha (2001): Deutsche Grammatik. Ein Handbuch für den Ausländerunterricht. Berlin, München: Langenscheid. 
Höche, Silke (2009): Cognate Object Constructions in English: A Cognitive-linguistic Account. Tübingen: Narr.

Horita, Yuko (1996): English Cognate Object Construction and their Transitivity. In: English Linguistics 13, S. 221-247.

Horrocks, Geoffrey \& Melita Stavrou (2010): Morphological Aspect and the Function and Distribution of Cognate Objects Across Languages. In: Rappaport Hovav, Malka/Doron, Edit \& Ivy Sichel (eds.): Lexical Semantics, Syntax and Event Structure. Oxford: Oxford University Press, S. 284-308.

Iwasaki, Shin-ya (2007): A cognitive analysis of English cognate objects. In: Constructions 1. E-Journal: https://journals.linguisticsociety.org/elanguage/constructions/article/ view/58.html, S. 1-40.

Jacobsohn, Hermann (1933): Aspektfragen. In: Indogermanische Forschungen 51,

S. $292-318$.

Jespersen, Otto (1924): The Philosophy of Grammar. Reprinted 1935. London: Allen \& Unwin LTD.

Jones, Michael A. (1988): Cognate objects and the case filter. In: Journal of Linguistics 24, S. 89-110.

Kaufmann, Ingrid (1995): Konzeptuelle Grundlagen semantischer Dekompositionsstrukturen. Die Kombinatorik lokaler Verben und prädikativer Komplemente. Tübingen: Niemeyer.

Levin, Beth \& Tova R. Rapoport (1988): Lexical Subordination. In: Proceedings of the 24th Annual Meeting of the Chicago Linguistic Society, S. 275-289.

Krifka, Manfred (1989): Nominalreferenz und Zeitkonstitution. Zur Semantik von Massentermen, Individualtermen, Aspektklassen. München: W. Fink.

Krifka, Manfred/Pelletier, Francis J./Carlson, Gregory N./ter Meulen, Alice/Link, Godehard \& Gennaro Chiercha (1995): Genericity: An Introduction. In: Carlson, Gregory N. \& Francis J. Pelletier (eds.): The Generic Book. Chicago: Chicago University Press, S. 1-124.

Kuno, Susumu \& Ken-ichi Takami (2004): Functional Constraints in Grammar. On the unergative - unaccusative distinction. Chap. 4: „The cognate object construction and unergativity.“ Amsterdam: John Benjamins, S. 105-135.

Lavidas, Nikolaos (2014): Cognate arguments and the Transitivity Requirement in the history of English. In: Lingua Posnaniensis LVI (1), S. 41-59.

Langacker, Ronald W. (1987): Foundations of Cognitive Grammar. Vol. 1. Theoretical Prerequisits. Stanford: Stanford University Press.

Langacker, Ronald W. (1991): Foundations of Cognitive Grammar. Vol. 2. Descriptive Application. Stanford: Stanford University Press.

Leiss, Elisabeth (2009): Konstruktionsgrammatik versus Universalgrammatik. In: Wieland, Eins/Schmöe, Friederike (eds.): Wie wir sprechen und schreiben. Festschrift für Helmut Glück zum 60. Geburtstag. Wiesbaden: Harrassowitz, S. 17-28.

Macfarland, Talke (1995): Cognate objects and the argument/adjunct distinction in English. Northwestern University. (Ph.D. dissertation).

Maienborn, Claudia (2011): Event semantics. In: Maienborn, Claudia/von Heusinger, Klaus \& Paul Portner (2011) (eds.): Semantics. An international handbook of natural language meaning. Volume 1. (HSK 33.1), Berlin, New York: Mouton de Gruyter, S. 802-829.

Massam, Diane (1990): Cognate objects as thematic objects. In: Canadian Journal of Linguistics 35, S. 161-190. 
Michaelis, Laura A. (2003): Word meaning, sentence meaning and syntactic meaning. In: Cuyckens, Hubert/Dirven, René \& John R. Taylor (eds.): Cognitive Approaches to Lexical Semantics. Berlin, New York: de Gruyter, S. 163-210.

Mittwoch, Anita (1998): Cognate Objects as Reflections of Dadidsonian Event Arguments. In: Rothstein, Susan (ed.) (1998): Events and Grammar. Dordrecht, Boston, London: Kluwer, S. 309-332.

Moltmann, Friedericke (1989): Nominal and clausal event predicates. In: Proceedings of the Regional Meeting of the Chicago Linguistics Society (CLS) 25, S. 300-314.

Naruse-Shima, Ryoko \& Norio Shima (2013): Kognate Objekte im Englischen und Deutschen: Eine kontrastiv-semantische Analyse. Kyoto Sangyo University, S. 371-390.

Olsen, Susan (1991): Ge-Präfigierungen im heutigen Deutschen: Ausnahmen zu der „Righthand Head Rule“? Beiträge zur Geschichte der deutschen Sprache und Literatur 113, S. 332-366.

Paul, Hermann (1919): Deutsche Grammatik. Bd. 3. Teil IV: Syntax (erste Hälfte). Halle (Saale): Niememeyer.

Paul, Hermann (2007): Mittelhochdeutsche Grammatik. 25. Auflage. Neu bearbeitet von Thomas Klein, Hans-Jürgen Solms, Klaus-Peter Wegera. Mit einer Syntax von Ingeborg Schröbler. Neu bearbeitet und erweitert von Heinz-Peter Prell. (Sammlung kurzer Grammatiken germanischer Dialekte A. Hauptreihe 2). Tübingen: Niemeyer.

Pustejowsky, James (2000): Lexical Shadowing and Argument Closure. In: Ravin, Yæl \& Claudia Leacock (eds.): Polysemy: Theoretical and Computanional Approaches. Oxford: Oxford University Press, S. 68-90.

Quine, Willard V.O. (1960): Word and Object. Cambridge, Mass.: MIT Press.

Real Puigdollers, Cristina (2008): The nature of cognate objects. In: Proceedings ConSOLE XVI, Paris, S. 157-178.

Reiner, Erwin (1985): Zur „Figura Etymologica“ im Deutschen, Englischen und Französischen. In: Moderne Sprachen 29, S. 19-32.

Rostila, Jouni (2007): Konstruktionsansätze zur Argumentmarkierung im Deutschen. Tampere: Juvenes Print.

Ruge, Nikolaus (2015): einen slac slân. Kognate Objekte und figura etymologica in der deutschen Sprachgeschichte. In: Sprachwissenschaft 40.4., S. 413-452.

Sailer, Manfred. (2010): The Family of English Cognate Object Constructions. In: Müller, Stefan (Ed.) (2010): Proceedings of the $17^{\text {th }}$ International Conference on Head- Driven Phrase Structure Grammar, Université Paris Diderot, Paris 7, France. Stanford, CA: CSLI Publications, S. 191-211.

Vendler, Zeno (1957): Verbs and Times. In: The Philosophical Review LXVI, S. 143-160.

Welke, Klaus (2001): Was heißt 1., 2., 3. Argument? In: Thielemann, Werner/Welke, Klaus (eds.): Valenztheorie: Einsichten und Ausblicke. Münster: Nodus Publikationen, S. 169-190.

Welke, Klaus (2005): Deutsche Syntax funktional. Perspektiviertheit syntaktischer Strukturen. 2., bearbeitete Auflage. Tübingen: Stauffenburg.

Welke, Klaus (2009): Konstruktionsvererbung, Valenzvererbung und die Reichweite von Konstruktionen. In: ZGL 34, S. 514-543.

Welke, Klaus (2016): Attribution unter konstruktionsgrammatischem Aspekt. In: Hennig, Mathilde (ed.) (2016): Komplexe Attribution. Ein Nominalstilphänomen aus sprachhistorischer, grammatischer, typologischer und funktionalstilistischer Perspektive. (Reihe: Linguistik - Impulse \& Tendenzen 63.) Berlin, Boston: Mouton de Gruyter, S. 58-95. 
Winkler, Edeltraud (2009): Anna lächelte ihr freundliches Lächeln. Syntaktischer und semantischer Status von inneren Objekten im Deutschen. In: OPAL-Sonderheft 4/2009. (Online publizierte Arbeiten zur Linguistik). Mannheim: Institut für Deutsche Sprache, S. 126-145.

Winkler, Edeltraut (2015): Die Familie der Argumentstrukturmuster mit inneren Objekten im Deutschen. In: OPAL 1/2015 (Online publizierte Arbeiten zur Linguistik). Mannheim: Institut für Deutsche Sprache, S. 13-32. 